\title{
An analysis of the environments of intense convective systems in West Africa in 2003
}

\author{
Stephen D. Nicholls* \\ Department of Earth and Atmospheric Sciences, University at Albany, SUNY, Albany, NY 12222 \\ Karen I. Mohr \\ Laboratory for Atmospheres, NASA-Goddard Space Flight Center, Greenbelt, MD 20771
}

*Current affiliation

Department of Environmental Sciences

Rutgers University

14 College Farm Road

New Brunswick, NJ 08901

Submitted to Monthly Weather Review, December 2009

Corresponding author

Karen I. Mohr

Laboratory for Atmospheres

Code 613.1

NASA-Goddard Space Flight Center

Greenbelt, MD 20771

Voice: (301) 614-6360

Fax: (301) 614-5492

karen.mohr-1@nasa.gov 


\begin{abstract}
We investigated the local- and regional-scale thermodynamical and dynamical environments associated with intense convective systems in West Africa during 2003. We indentified convective system cases from TRMM microwave imagery, classifying each case by the system minimum $85-\mathrm{GHz}$ brightness temperature and by the estimated elapsed time of propagation from high terrain. The speed of the mid-level jet, the magnitude of the low-level shear, and the surface equivalent potential temperature $\left(\theta_{\mathrm{e}}\right)$ were greater for the intense cases compared to the non-intense cases, although the differences between the means tended to be small, less than $3 \mathrm{~K}$ for surface $\theta_{\mathrm{e}}$. Hypothesis testing of a series of commonly used intensity prediction metrics resulted in significant results only for low-level metrics such as convective available potential energy and not for any of the mid- or upper-level metrics such as $700-\mathrm{hPa} \theta_{\mathrm{e}}$. None of the environmental variables or intensity metrics by themselves or in combination appeared to be reliable direct predictors of intensity. In the regional scale analysis, the majority of intense convective systems occurred in the surface baroclinic zone where surface $\theta_{\mathrm{e}}$ exceeded $344 \mathrm{~K}$ and the $700-\mathrm{hPa}$ zonal wind speeds were less than $-6 \mathrm{~ms}^{-1}$. Fewer intense cases compared to non-intense cases were associated with African easterly wave troughs. Fewer than $25 \%$ of our cases occurred in environments with detectable Saharan dust loads, and the results for intense and non-intense cases were similar. Our results for the regional analysis were consistent with the seasonal movement of the WAM and the intertropical front, regional differences in topography, and AEW energetics.
\end{abstract}




\section{Introduction}

Multicellular organized convection capable of producing large hail and strong winds can be inferred from high frequency microwave imagery by large negative brightness temperature anomalies, making regional and global censuses possible (e.g., Mohr and Zipser 1996; Nesbitt et al. 2000; Toracinta et al. 2002; Cecil et al. 2005; Zipser et al. 2006). Because West Africa was identified as a hotspot of intense organized convection in the global survey of Zipser et al. (2006), an improved understanding of the environments most likely to allow strong convection to develop and organize is of great interest to the forecasters and farmers in the region. In this study, we analyze the local and regional-scale thermodynamical and dynamical environments associated with intense convective systems in West Africa during the 2003 wet season.

The review paper of Houze (2004) summarizes the initial development of organized convection as driven by buoyant convective updrafts (i.e., parcel lifting) then later by slantwise ascent. The layer of slantwise ascent (i.e., region of slanted updrafts) is potentially unstable and thus overturns, resulting in the upward movement of high equivalent potential temperature $\left(\theta_{\mathrm{e}}\right)$ air. Here, we define the speed of the slanted updrafts as the intensity of the convective system. There are many observational (e.g., Frank 1978; Barnes and Sieckman 1984; Alexander and Young 1992; LeMone et al. 1998; Johnson et al. 2005) and modeling (e.g., Weisman and Klemp 1982, 1984; Rotunno et al. 1988; Fovell and Ogura 1989; Lafore and Moncrieff 1989; Lucas et al. 2000; Robe and Emanuel 2001; Weisman and Rotunno 2004; Cheng 2005a, b; James et al. 2005; McCaul et al. 2005; Takemi 2006, 2007a, b) studies of organized convection that have examined how the characteristics (propagation speed, intensity, organization, longevity) of convective systems are sensitive to the characteristics of the moist stratification of the overturning layer and environmental shear. Three general organizational modes are described, 
depending on the environmental shear: non-linear (weak shear), linear shear-perpendicular (moderate or more low-level shear), and linear shear-parallel [moderate or more mid-level shear, additional environments described in Johnson et al. (2005)]. The majority (30 to 1) of organized convection in the global study by Tsakraklides and Evans (2003) exists in one of the linear organizational modes. Robe and Emanuel (2001) and Cheng (2005a, b) describe how each of three modes may arise, showing that optimal organization of the linear modes occurs when the depth of the shear layer below $400 \mathrm{hPa}$ is comparable to the cold pool depth. Cold pool development is inversely related to the environmental static stability: strong, deep cold pools are more likely in environments with low static stability (Lafore and Moncrieff 1989; James et al. 2005; Takemi 2006, 2007a, b). Such cold pools make possible the strong low-level convergence and fast slantwise ascent of high $\theta_{\mathrm{e}}$ air that characterize intense convective systems.

Several West African studies have offered general descriptions of environments likely to produce intense convective systems. Frank (1978) observed that both weak non-linear and intense linear (shear-perpendicular, i.e., squall line) convective systems developed in environments with similar temperature, moisture, wind, and vertical motion fields, but the vertical wind shear was twice as strong in the squall line environments. Frank (1978) also associated squall lines with a strong African easterly jet (AEJ) and triggering mechanisms such as approaching African easterly wave (AEW) troughs. In contrast, Rowell and Milford (1993) found that neither AEW troughs nor the speed of the AEJ were significant in the development of intense convective systems. In their conceptual model, the environment of intense convective systems consists of a deep monsoon layer within the West African monsoon (WAM) trough, is conditionally unstable as a result of a strong diurnal cycle, is near high terrain $(>500 \mathrm{~m})$, and possesses strong low-level wind shear. They listed three possibilities for releasing low-level 
instability in high terrain environments: forced ascent, updrafts caused by the relatively warm air on terrain surfaces, or boundary layer convergence lines. Hodges and Thorncroft (1997) described much the same environment as Rowell and Milford, namely, high conditional and potential instability, strong vertical wind shear, and orography. Roca et al. (2005) documented enhanced convective activity in the Sahel for several days after mid-tropospheric dry air intrusions originating in the extratropics. The organization and speed of movement of the convective systems in IR imagery indicated a high proportion of strong squall lines. Mohr and Thorncroft (2006, hereafter MT06) found that the peak activity of intense convective systems was within $0.5^{\circ}$ downstream of high terrain and just north of the AEJ where high convective available potential energy (CAPE) and high low-level shear often occurs simultaneously. Different areas of orography became convective focal points following the seasonal migration of the AEJ, whereas the peak of activity of weak convective systems remained south of $10 \mathrm{~N}$ throughout the wet season.

The Saharan air layer (SAL) results from outflow from the Saharan heat low and dry convection of dust-laden air (Carlson and Prospero 1972; M'bourou et al. 1997; Karyampudi et al. 1999). Aerosol concentrations are determined by the background dust due to dry convection and dust outbreaks transported by strong mid-level winds. The dust outbreaks can be forced by convectively generated gravity currents (Flamant et al. 2007) or by synoptic-scale lifting due to AEWs (Karyampudi et al. 1999) or from the penetration of mid-latitude upper level troughs (Jankowiak and Tanré 1992). The effect of dust aerosols on moist convective cells is both direct, from the scattering and absorption of solar radiation (e.g., Coakley et al. 1983; Coakley and Cess 1985; Charlson et al. 1991), and indirect, as cloud condensation nuclei (e.g., Twomey 1977; Albrecht 1989; Rosenfeld 2000). The indirect effect could potentially benefit convection by 
inhibiting droplet growth below the freezing level and reducing condensate loading (Rosenfeld and Lensky 1998; Williams and Stanfill 2002). The direct effect may reduce convection by increasing solar heating at the top of the boundary layer, reducing relative humidity, and increasing cooling at the surface (Ackerman et al. 2000; Ramanathan et al. 2001a). During the 1998 and 1999 Indian Ocean Experiment (INDOEX) studying the direct effect on marine clouds, the majority of deep convection occurred outside of pollution tracks (Ramanathan et al. 2001a; Ramanathan et al. 2001b). The modeling study by Fan et al. (2008) accounted for both the direct and indirect effects of aerosol optical properties on deep convective clouds in an urban environment. Cloud fraction and a host of cloud microphysical properties including ice particle number concentration decreased by $15 \%$ or more compared to an aerosol-free control. In INDOEX, boundary layer stabilization appeared to overwhelm any positive indirect effect on the cloud microphysics, resulting in less deep convection in dusty areas.

The current study makes use of a large database and a combination of surface and remote sensing data and operational analysis to quantify key thermodynamical and dynamical variables distinguishing the environments of individual convective systems. We compare the environments of both intense and non-intense events during the 2003 wet season. We examine the relationship of AEWs and Saharan aerosols to the events in the database. The former is of some dispute in previous work, and there is little work published on the latter with respect to individual convective systems. With this study, we have attempted to provide a more detailed description of the environment of intense convective systems at multiple spatial scales.

\section{Data and Methods}

a. Composition of event database 
The 2003 wet season was characterized by an enhanced monsoon circulation and an associated northward shift of the mean ITCZ, making it the second wettest year since 1990 and in the $70^{\text {th }}$ percentile for annual rainfall since 1950 (Levinson and Waple 2004). This season provided ample opportunity to develop a large intense convective system database. Also important was access to a full wet season of data from the Tropical Rainfall Measuring Mission (TRMM) Microwave Imager (TMI) and the Aqua satellite's Moderate Imaging Spectroradiometer (MODIS). We chose a study area $3^{\circ}-21^{\circ} \mathrm{N}, 17^{\circ} \mathrm{W}-30^{\circ} \mathrm{E}$ (Figure 1) and an observation period of May to September for its frequent intense convective system activity (Mohr and Thorncroft 2006). Analysis of distances and proximities described in this section used the geographical information systems software ArcView ${ }^{\circledR} 9.2$ and $\operatorname{ArcInfo} \circledast 3.4$.

The location and characteristics of convective systems during the May-Sep 2003 observation period were derived from TMI data at $85 \mathrm{GHz}$. The $85-\mathrm{GHz}$ horizontally- and vertically-polarized brightness temperature images were combined into one image of polarization-corrected brightness temperatures (PCT) by a simple linear equation (Spencer et al. 1989). The use of polarization-corrected brightness temperatures makes it possible to distinguish precipitating cloud from non-raining background, eliminating identification errors due to emissivity discontinuities resulting from reflective surface types (e.g., water, desert sand, ice). Minimum PCT is a useful proxy for system intensity because it is related to the production by convective updrafts of large ice hydrometeors (graupel and hail) that scatter high-frequency microwave radiation from a satellite's field of view (Spencer et al. 1989; McGaughey et al. 1996). The methodology used to identify convective systems from the $85-\mathrm{GHz}$ PCT imagery is described in Mohr (2004). The pattern recognition algorithm applied to the PCT imagery identified convective systems as contiguous image pixels with PCTs of $255 \mathrm{~K}$ or lower. We 
recorded the date, overpass time, location, minimum PCT, and size of each convective system identified. Since a convective system implies a cluster of convective cells rather than individual cumulonimbus, we define a convective system to be at least $64 \mathrm{~km}^{2}$, implying at least 4 contiguous $85 \mathrm{GHz}$ pixels with a PCT below $255 \mathrm{~K}$. This definition is the same used in Mohr et al. (2009) and results in the identification of 15771 convective systems for the 2003 wet season.

To distinguish between intense and non-intense convective systems, we used the classification scheme of MT06. The MT06 classification scheme was based on the rankings of minimum PCT of all of the convective systems occurring in 1998, a near- to slightly above average year for precipitation. They calculated a $10^{\text {th }}$ percentile of $135 \mathrm{~K}$ and designated all convective systems in the $10^{\text {th }}$ percentile or less as intense. All convective systems above the $10^{\text {th }}$ percentile were designated non-intense. Ranking of convective systems for all the TRMM years since 1998 by Mohr et al. (2009) revealed that the value of the $10^{\text {th }}$ percentile changes less than $5 \%$ year-to-year, making it a reliable division between intense and non-intense events.

A second classification scheme involved each convective system's relationship to high terrain. In Hodges and Thorncroft (1997) and MT06, most convective systems form on and occur near high terrain. The high terrain classification scheme was based on Rowell and Milford (1993), in which high terrain was $500 \mathrm{~m}$ or greater elevation, and the typical life span of a propagating convective system was $6 \mathrm{~h}$. In Barnes and Sieckman (1984), the line speed of observed West African convective lines was $\pm 1 \mathrm{~m} \mathrm{~s}^{-1}$ of the maximum mid-tropospheric wind normal to the line. Since the AEJ height is typically observed between $600-700 \mathrm{hPa}$, we used the 700-hPa winds from the European Centre for Medium-Range Weather Forecasts (ECMWF) operational analysis to find the estimated line speeds for the intense convective system cases. For each 6-h interval of the ECMWF operational analysis, we overlaid a map of 700-hPa vector 
winds, convective system locations in that time interval, and a map of terrain contours. For each of the intense cases not already located over high terrain, we set a line against the wind vector direction from its location to the nearest point on a 500-m terrain contour and calculated the distance from the storm location to the terrain contour along the line. This distance was divided by the average steering wind speed along the line to estimate the time elapsed since initiation over high terrain. We designated an intense convective system as near high terrain if the distance from the nearest 500-m elevation contour was less than the product of $6 \mathrm{~h}$ and the $700-\mathrm{hPa}$ wind speed. Based upon our two classification schemes, we derived our four case types: near-terrain intense, terrain-intense, far-intense, and non-intense. Because there were many more non-intense cases than intense cases, we limited the local environmental analysis of non-intense cases to those no more than $0.25^{\circ}$ from the nearest $500 \mathrm{~m}$ terrain contour. This filter was designed to insure that the non-intense cases would have weak, mature convection rather than decaying convection. Table 1 lists the number of convective systems of each case type.

\section{b. Constructing the local environment}

During the study period, there were 8 active sounding sites in West Africa as shown in Figure 1. Table 2 contains information about each site including the number of radiosonde launches and observation times. We matched a sounding to a case only if that case was within $3^{\circ}$ $(\sim 300 \mathrm{~km})$ of the station and six hours after the sounding launch. After applying this filter, there were a total of 320 usable soundings matched to 1477 cases. To eliminate multiple assignments, we used distance and case type to filter the matches, favoring the less common intense cases. For example, if a sounding matched several non-intense cases and a couple of terrain-intense cases, we matched the sounding only to the closest terrain-intense case. Because the number of cases (320) matched to in-situ soundings was only a small percentage of the overall event 
database and limited geographically, we turned to ECMWF operational analysis to expand our case database.

Using the location, date, and time information for each case, we extracted the corresponding meteorological data at the surface and at each pressure level from the nearest gridcell in the ECMWF operational analysis. To verify the soundings constructed from the ECMWF operational analysis, we compared a selection of in-situ soundings at each of the 8 sounding sites to the corresponding constructed soundings (hereafter referred to as EOAsoundings). The EOA-soundings satisfactorily resembled smoothed versions of the in-situ soundings. An example comparison is depicted in Figure 2. The EOA-sounding temperature curves were within $5^{\circ} \mathrm{C}$ of the in-situ curves, although the dewpoint curves could be as much as $10^{\circ} \mathrm{C}$ different in the mid-levels. Although the EOA-soundings do not have the same vertical resolution as the in-situ soundings, we were able to construct EOA-soundings and extract some information about the local environment for 4750 cases to compare with the results from the 320 cases with in-situ soundings.

For both sets of soundings, we calculated $\theta_{\mathrm{e}}$ at the surface, $850 \mathrm{hPa}$, and the boundary layer (BL). The $\mathrm{BL} \theta_{\mathrm{e}}$ is a weighted average of $\theta_{\mathrm{e}}$ from the surface to $850 \mathrm{hPa}$. Based on the methodology of Lucas et al. (2000), vertical wind shear was calculated from the in-situ sounding data for three layers: surface to low-level maximum zonal wind (hereafter, low-level wind shear), low-level maximum zonal wind to $6000 \mathrm{~m}$ (hereafter, mid-level wind shear), low-level maximum zonal wind to $10300 \mathrm{~m}$ (hereafter, deep-layer wind shear). The maximum zonal wind below $600 \mathrm{hPa}$ is typically recorded at a significant level in the in-situ soundings and, depending on the time of year, be associated with the height and speed of the AEJ. The 700-hPa zonal wind 
is the best approximation of the AEJ speed in the EOA-soundings, and the low-level shear was calculated for the surface to $700-\mathrm{hPa}$ layer. Because of the coarse vertical resolution in the operational analysis, we did not make calculations for mid- and deep-levels.

\section{c. Constructing the regional environment}

From ECMWF operational analysis, we constructed Hovmöller plots of zonal and meridional wind components and maps of vector winds to examine synoptic- to regional-scale circulation features at $925,850,700$, and $200 \mathrm{hPa}$ for $18^{\circ} \mathrm{W}-40^{\circ} \mathrm{E}$. We also compiled 9-day average maps of $700-\mathrm{hPa}$ zonal winds and surface $\theta_{\mathrm{e}}$. A 9-day average removes the diurnal and synoptic-scale variability such as the nocturnal inversion and wind anomalies due to AEWs. Cases were plotted on the 9-day maps to reveal relationships between case distribution and regional circulation features such as the AEJ. In the regional analysis, we used the subdivisions indicated in Figure 1 to detect intra-regional differences due to the seasonal cycle of the WAM. The subdivisions were based on land cover (primarily forest, savanna, or semi-desert) and, for the forest and savanna zones, subdivided again into east and west regions based on orography. The east regions contained the majority of terrain greater than 500-m elevation.

The 700-hPa winds were also useful in tracking AEW troughs to analyze their relationships to our intense cases. To perform the AEW analysis, we combined an algorithm developed by Berry et al. (2007) to identify AEW troughs and our own algorithm finding the nearest AEW trough point to each case. The threshold values for curvature vorticity minimum, minimum, trough length, and smoothing of the Berry et al. algorithm had to be reduced to reflect our longer observation period (May-Sep for our study vs. Jul-Sep for Berry et al.). African easterly waves are typically weaker during the beginning of May and at their most intense later 
in the season. The lower threshold values increased the amount of noise, but we were able to successfully observe AEWs during all months of our study period.

To assess AEW trough influence on cases, we considered both the distance from cases to the nearest AEW trough and trough length. We specified four different distance criteria, 2 relative and 2 fixed distances: 1 -AEW trough length, $1 / 2-\mathrm{AEW}$ trough length, 200-km, and 500$\mathrm{km}$. Typically, an AEW trough length is $250-800 \mathrm{~km}$, and the range of AEW influence varies with both trough size and intensity (Burpee 1972; Reed et al. 1977). The 200-km and 1/2-AEW trough length criteria were chosen to reflect the influence of smaller and/or less intense waves. The distance categories are inclusive: the 500-km category counts all convective systems within $500 \mathrm{~km}$ from the nearest AEW trough, including those within $200 \mathrm{~km}$.

For our depiction of dust in the regional environment, we obtained the MODIS aerosol optical depth product. The aerosol optical depth product is based on an algorithm called "Deep Blue" which scans for aerosols at a wavelength of $550 \mathrm{~nm}$. An analysis of retrievals processed using Deep Blue is in Hsu et al. (2006). Deep Blue is capable of detecting dust over high albedo surfaces such as the Sahara Desert. For this study, the only available Deep Blue-processed aerosol optical depth product was from the Aqua satellite. Hence, our analysis is based on the twice-daily overflights of one polar-orbiter. Aerosol optical depth is a unitless quantity $\left(\mathrm{kg} \mathrm{m}^{3}\right.$ $\mathrm{kg}^{-1} \mathrm{~m}^{-3}$ ), hereafter called "optical depth units". A pixel with an optical depth of 0.0 indicates the limit of sensor detection of aerosol dust concentration, and a pixel greater than 5.0 indicates an atmospheric footprint nearly opaque with dust. Pixels over water or below the detection limit over land are coded with a flag value (-9999). For 2003, the optical depth unit range was 0.0-7.0, although the majority of pixels were less than 1.0. The aerosol optical depth images depicted the 
aerosol dust concentration in the environment of our cases and allowed us to evaluate seasonal and multi-day variations in aerosol optical depth with respect to our case locations.

\section{The Local Environment}

\section{a. Analysis of observed and derived soundings}

Tables 3 and 4 summarize the analysis of the in-situ and EOA-sounding cases. Our hypothesis testing covered both normally and non-normally distributed variables. For normally distributed variables such as temperature, we conducted one-tailed heteroscedastic two-sample Student's t-tests at $\alpha=0.05$ between the intense and non-intense cases. For non-normally distributed variables such as CAPE, we applied the non-parametric Mann-Whitney test in the same manner. The limited number of in-situ terrain cases made it impossible to conduct a statistically meaningful hypothesis test vs. the far-intense cases. Thus, only the EOA-sounding terrain-intense vs. far-intense cases are tested.

In both tables, the speed of the mid-level jet, the magnitude of the low-level shear, and the surface $\theta_{\mathrm{e}}$ are significantly greater for the intense cases compared to the non-intense cases. For the in-situ cases, the height of the AEJ was significantly different, but the magnitudes of the mid- and deep-level shear and the $850-\mathrm{hPa}$ and $\mathrm{BL} \theta_{\mathrm{e}}$. were not significantly different. The higher, faster jet would contribute to the greater low-level shear in the intense cases. The mean mid-level shear is higher for the intense in-situ cases, and the difference in the means is only slightly smaller than the means of the low-level shear. However, the samples in the mid-level shear t-tests had nearly identical variances, whereas the variance of low-level shear of the in-situ non-intense cases was twice the variance of the in-situ intense cases. There are some notable differences between Tables 3 and 4 due to the larger case database, greater variety of 
thermodynamic environments in the EOA-sounding analysis, and resolution of the model grid. In Table 4 , there are significant results at $850-\mathrm{hPa}$ and $\mathrm{BL} \theta_{\mathrm{e}}$ because the variances were large even though the differences in the means were small. The mean surface and BL $\theta_{\mathrm{e}}$ of the farintense cases is lower than the terrain cases in Table 3 and higher in Table 4. The regional analysis in the next section demonstrates how it is more often that far-intense cases are located in the regional surface baroclinic zone (Table 4) even as point measurements near high terrain may record locally very high temperatures and humidities in the pre-storm environment (Table 3).

Histograms of surface $\theta_{\mathrm{e}}$ and mid-level wind speed in Figure 3 clarify why we obtained significant results. In Figure 3a, the number of in-situ cases peaks in the $350-360 \mathrm{~K}$ bin and in the $340-350 \mathrm{~K}$ bin for the EOA-sounding cases. Above $360 \mathrm{~K}$, there are $30 \%$ more intense insitu cases vs. $15 \%$ more non-intense in-situ cases. Above $350 \mathrm{~K}$, there are $24 \%$ more EOAsounding intense cases vs. $17 \%$ more EOA-sounding non-intense cases. Below $340 \mathrm{~K}$, there were only 2 in-situ cases ( 1 intense, 1 non-intense). For the EOA-sounding cases, $3 \%$ of the non-intense and $1 \%$ of the intense cases were below $330 \mathrm{~K}$. In Figure $3 \mathrm{~b}$, there are $34 \%$ more far-intense cases above $350 \mathrm{~K}$ vs. $18 \%$ more terrain- and near-terrain intense cases. In Figure 3c, there are more intense cases above $10 \mathrm{~m} \mathrm{~s}^{-1}, 65 \%$ vs. $43 \%$ for the in-situ cases and $42 \%$ vs. $23 \%$ for the EOA-sounding cases. Despite differences in resolution and geographical coverage, both sets of cases have similar distributions. More intense cases occur above the peaks of the surface $\theta_{\mathrm{e}}$ and mid-level wind speed histograms. It is important to note that few non-intense and very few intense cases occur $10 \mathrm{~K}$ below the surface $\theta_{\mathrm{e}}$ histogram peak. Only $5 \%$ intense in-situ and $15 \%$ of the intense EOA-sounding cases occurred in the $<5 \mathrm{~m} \mathrm{~s}^{-1}$ bin.

\section{b. Analysis of intensity prediction metrics}


We tested an additional series of variables and derived indices from the in-situ cases to assess their value for predicting intensity of West African convective systems. Our list of variables was derived from the papers in our literature review. The following variables triggered significant results for non-intense vs. intense hypothesis tests:

- Pseudo-adiabatic and reversible CAPE (intense > non-intense)

- Pseudo-adiabatic and reversible convective inhibition (CIN, intense $>$ non-intense)

- Lifted index (intense $<$ non-intense)

Figure 4 contains the cumulative frequency distributions of pseudo-adiabatic CAPE for intense and non-intense convective systems. Reversible CAPE distributions (not shown) were similar to those in Figure 4. Although there is no difference between the far- and terrain-intense distributions, there is a significant gap between the intense and non-intense distributions from $200 \mathrm{~J} \mathrm{~kg}^{-1}$ to $2000 \mathrm{~J} \mathrm{~kg}^{-1}$ ( $75^{\text {th }}$ percentile). Above the $75^{\text {th }}$ percentile, there are almost as many non-intense cases as intense cases. The large number of cases with CAPE below $500 \mathrm{~J} \mathrm{~kg}^{-1}$ for both non-intense and intense cases reflect the local timing (midnight) of the $0 \mathrm{Z}$ sounding at the typical diurnal low in CAPE (Dai 2001; Zhang 2003).

Testing the following variables did not produce significant results:

- Height of the level of free convection

- TEJ height and speed

- Precipitable water

- $\theta_{\mathrm{e}}$ at $700 \mathrm{hPa}$

- Minimum $\theta_{\mathrm{e}}$ and height $(z)$ of the minimum $\theta_{\mathrm{e}}$

- Static stability of convectively unstable layer, $\Gamma_{C U L}=\frac{T_{z\left(\theta_{e \min }\right)}-T_{z\left(\theta_{\text {esc }}\right)}}{z_{(\theta e \min )}-0}$ 
Takemi $(2006,2007 \mathrm{a}, \mathrm{b})$ used $\Gamma_{C U L}$ to predict convective intensity in simulated squall lines. Although the surface $\theta_{\mathrm{e}}$ test had a significant result, neither the minimum $\theta_{\mathrm{e}}$ nor the height of the minimum $\theta_{\mathrm{e}}$ had significant results, resulting in their derived index in (1) failing to reach significance.

\section{The Regional Environment}

\section{a. Example of the relationship to the surface baroclinic zone}

Figure 5 contains the example of the strong relationship between intense convective systems and the surface baroclinic zone. In Figures $5 \mathrm{a}$ and $5 \mathrm{~b}$, the intense cases are concentrated within the gray-shaded easterly wind contours versus a more diffuse distribution of non-intense cases. Unlike the intense cases, the non-intense cases show no particular orientation toward the belt of strongest easterly winds. Figures $5 \mathrm{c}$ and $5 \mathrm{~d}$ reveal a similar relationship to surface $\theta_{\mathrm{e}}$ with the intense cases mostly clustered within the shaded $344 \mathrm{~K}$ contour and the non-intense cases distributed widely. Many of the non-intense cases occur south of the shaded contours in the high terrain east of $8^{\circ} \mathrm{E}$. Consistent with Table 4 , there are proportionally more terrain-intense cases than far-intense cases occurring outside the shaded areas in Figures 5a and 5c. Since the position of the AEJ is linked to the surface baroclinic zone, indicated by the gradient in surface $\theta_{\mathrm{e}}$, the results in both sets of panels are consistent with each other and with previous work (Parker et al. 2005; Mohr and Thorncroft 2006). For the sake of brevity, we did not include panels from additional 9-day periods from May to September that demonstrate the same spatial correlation between the AEJ, surface $\theta_{\mathrm{e}}$, and intense convective systems. Detailed discussion of the AEJ and intense cases with respect to the seasonal cycle can be found in MT06.

\section{b. Relationship to African easterly waves}


Studies of AEWs have discussed the relationship of AEWs to the development of organized convection (e.g., Reed et al. 1977; Reed 1980; Berry et al. 2007; Hsieh and Cook 2007). The dynamics of AEWs can transform an otherwise marginally unfavorable environment to a favorable environment for convective system development. The most favorable region for initiation is near the southern end of the AEW trough due to moisture anomalies generated by enhanced synoptic-scale meridional advection. Further development takes place as the convective system propagates more quickly than the trough, moving into the region ahead of the trough where there is favorable synoptic-scale adiabatic ascent. Figure 6 documents the number of convective systems that occurred in 2003 at our 4 distance criteria (inclusive categories). In Figures $6 \mathrm{a}$ and $6 \mathrm{~b}, 30 \%$ of all cases were within $500 \mathrm{~km}$, the most generous criterion, dropping to $7 \%$ for the most restrictive criterion, $200 \mathrm{~km}$. The percentages for the forest subdivisions and the western subdivisions tend to be higher than the regional percentages, with the Sahel and east savanna subdivisions less than the regional percentages. Terrain- and near-terrain intense cases (Figure 6c) are least often located near AEW troughs at all distance criteria. Far-intense cases are only slightly $(<5 \%)$ more often located near an AEW trough than the terrain intense cases, and $2 \%-10 \%$ less likely than the non-intense cases.

Monthly variations associated with the seasonal cycle are apparent in Figure 6d. The percentages for the Sahel and the east savanna never exceed $15 \%$ in any month. For the Sahel, they exceed $10 \%$ in August at the height of its wet season and in June when AEWs would be most beneficial just prior to the WAM jump. Consistent with WAM migration, the east savanna exceeds $10 \%$ one month earlier (May and July) than the Sahel. The east forest distribution varies less than $10 \%$ except in August when AEW track density is at a minimum in this subdivision (Hopsch et al. 2007). The Guinea Highlands span both western subdivisions. In conjunction 
with AEWs, they are associated with the development of coherent potential vorticity anomalies and thus outbreaks of convective activity, peaking in May and October (not covered) in the west forest and August-September in the west savanna (Hopsch et al. 2007).

\section{c. Relationship to Saharan aerosol}

Figure 7 depicts the MODIS aerosol optical depth images for 4 representative days in the middle of May-August. The intense and non-intense cases for each day are plotted for reference. In the May image (Figure $7 \mathrm{a})$, there is a small cluster of non-intense cases $\left(1^{\circ} \mathrm{E}\right.$, $17^{\circ} \mathrm{N}$ ) associated with an upper-level mid-latitude trough (discussed later). Few cases occur in areas with detectable dust loads, although the June image (Figure 7b) has a higher proportion of cases in dusty areas compared to the other months. Lidar observations of dust outbreaks due to AEWs place the maximum dust concentration just poleward of the AEJ axis (Karyampudi et al. 1999). In the July image (Figure 7c) there are dark gray patches indicating high dust concentrations west of $27^{\circ} \mathrm{E}$ and west of $8^{\circ} \mathrm{W}$. These outbreaks are poleward of the jet axis in Figure 5a and within a wavelength of approaching AEWs (not shown). The far-intense cases near $8^{\circ} \mathrm{W}$ also occur poleward of the AEJ and ahead of an AEW, but not in the dustiest areas. Most of the upstream area of these cases has non-detectable dust loads. The August (Figure 7d) image has fewest cases of any case type in dusty areas. Because of the general similarity of August and September images, only August is represented.

To clarify the how few cases occurred in detectable dust loads, Figure 8 includes the empirical cumulative frequency distributions (CDF) for aerosol optical depth for each month and the seasonal mean for each case type. The curves are truncated at $80 \%$ to focus on the top of the curves where dust concentrations are greater than 0.1 optical depth units. The seasonal mean 
CDFs for non-intense (Figure 8a) and intense (Figure 8b) cases are highly similar $(p=0.36)$. The near- and terrain-intense cases (Figure 8c) are to the left of the intense seasonal mean, and the far-terrain cases (Figure 8d) are about the same distance to the right. In all panels, the June CDF is to the right of the other months, and August and September are left of the seasonal mean and similar to each other. In June north of $10^{\circ} \mathrm{N}$ prior to the WAM jump, there is an increase in convective activity along the intertropical front, a surface confluent zone between the increasing but still shallow layer of southwesterly monsoon flow and the dusty northeasterly Harmattan (Sultan and Janicot 2003). During this time, there are more cases occurring near measurable dust concentrations than any other time of the wet season.

Comparing Figures 8a and 8b, May and July are on opposite sides of the seasonal mean. In May, synoptic-scale lifting and vorticity anomalies associated upper-level mid-latitude troughs penetrating as far south as $15^{\circ} \mathrm{N}$ can assist in convective initiation (Figure 7a) and in dust outbreaks (Jankowiak and Tanré 1992). The convective systems north of $15^{\circ} \mathrm{N}$ in Figure $7 \mathrm{a}$ and in our May database are all non-intense, consistent with a surface baroclinic zone near $5^{\circ} \mathrm{N}$ in May. After the WAM jump, any time from late June to mid-July, the enhanced monsoon flow displaces the intertropical front northward (Hagos and Cook 2007). The intense convective system CDFs reflect the seasonal movement of the surface baroclinic zone and intertropical front, closer (June, early July) and farther (May, August, September) from dusty areas. Much of the important high terrain in the study region and thus the terrain-intense cases (Figure 8c) are south of $12^{\circ} \mathrm{N}$. Far-intense cases (Figure 8d) that tend to propagate west-northwestward along the AEJ axis are more likely to evolve in environments closer to dusty areas.

\section{d. Influence of the bi-weekly mode of variability}


From late June to early September, the climatological position of the TEJ axis west of $30^{\circ} \mathrm{E}$ is across the Guinea Coast, approximately $5^{\circ} \mathrm{N}$ (Hastenrath 1991). In Figure 9 are Hovmöller plots of the $200-\mathrm{hPa}$ zonal and meridional winds for the inland latitude belt where the majority of our cases occur. In Figure 9a, the TEJ is visible between Julian days 165 and 260, with westerly winds prevailing before and after the TEJ. The similar timing in the establishment of the TEJ and the WAM jump results in the majority of intense cases and many of the nonintense cases occurring north and west of the highest easterly winds. Much of the study region between days $165-260$ is characterized by a relatively homogeneous $200-\mathrm{hPa}$ wind field, accounting for the non-significant result reported in Section $3 \mathrm{~b}$. Northerly wind anomalies (Figure 9b) occur most frequently and are strongest before day 165 and after day 260 . After day 165 , the northerly wind anomalies are weaker, but more regular. Jankowiak and Tanré (1992) observed that Saharan dust outbreaks associated with upper-level mid-latitude troughs tend to occur prior to the WAM jump. A northerly wind anomaly due to a mid-latitude trough occurs in Figure $9 \mathrm{~b}$ between days $140-145$, coinciding with the dust outbreak and convective activity north of $15^{\circ} \mathrm{N}$ in Figure $7 \mathrm{a}$.

The bi-weekly (15-20) day mode of variability described in previous studies (Sultan et al. 2003; Mounier and Janicot 2004; Mounier et al. 2008; Mohr et al. 2009) is visible in Figures $9 \mathrm{~b}$ and 9c. Mounier et al (2008) dubbed this phenomenon the "quasi-biweekly zonal dipole" and described it as the result of equatorial atmospheric dynamics modified by land surface processes in West Africa. Between days 165-260, the peaks in both time series in Figure 9c coincide with northerly wind anomalies in Figure 9b. Nicholson et al. (2007) and Mounier et al. (2008) discuss the positive effect of these upper-level northerly anomalies on precipitation. The bi-weekly precipitation maxima are a result of the amplification of moist low-level westerly flow by these 
Kelvin wave-like disturbances propagating eastward between two poles, the mid-Atlantic to the Guinea Coast (Mounier et al. 2008). The intense convective system time series has the same frequency as the "all" convective system time series throughout the wet season. This includes weeks before and after the TEJ, where northerly wind anomalies due to the Kelvin wave-like disturbances can be difficult to distinguish from those due to mid-latitude troughs.

\section{Implications for Operational Forecasting}

Determining the likelihood that intense convective systems will develop during the wet season does not fall into place as a straightforward forecasting recipe. The differences in the means in Tables 3 and 4 are small and the shifts of the histograms of Figure 4 subtle, even when they trigger a significant result in hypothesis testing. In the evaluation of the intensity prediction metrics, only the low-level metrics had significant results, but appear less useful in high CAPE environments (Figure 4). The non-significant results for the mid-level prediction metrics at first appear to contradict earlier studies. Faster moving squall lines in Barnes and Sieckman (1984) tended to have a lower $700-\mathrm{hPa} \theta_{\mathrm{e}}$. Takemi $(2006,2007 \mathrm{a}, \mathrm{b})$ used $\Gamma_{C U L}$ (Equation 1) to predict convective intensity in simulated squall lines, and both Takemi (2006) and McCaul et al. (2005) simulated stronger cold pools and more vigorous convection in low precipitable water environments.

To interpret the mid-level results, it is important to consider the layered structure of the troposphere south of $20^{\circ} \mathrm{N}$ during the WAM. Outflow from the Saharan heat low contributes Saharan air to an elevated mixed layer whose height above ground level and depth depends on the depth and humidity of the monsoon layer below it (Parker et al. 2005). Additional contributors to dry adiabatic mid-levels include extra-tropical intrusions (Roca et al. 2005) and 
in-situ subsidence over the northward and downward sloping monsoon layer (Parker et al. 2005). The elevated mixed layer, extending as much as $8^{\circ}$ south of the axis of the baroclinic zone, results in a large area with highly similar mid-levels, dry through a deep layer of the troposphere above the boundary layer. The mean precipitable water for in-situ cases was $41 \mathrm{~mm}$ for intense cases and $42 \mathrm{~mm}$ non-intense cases. These means are closer to the low $(30 \mathrm{~mm})$ than to the high $(60 \mathrm{~mm})$ precipitable water simulations in McCaul et al. (2005). Only $20 \%$ of the in-situ cases had precipitable water outside one standard deviation ( $8 \mathrm{~mm}$, both case types), and only 1 intense and 2 non-intense cases had precipitable water greater than $60 \mathrm{~mm}$. There were non-intense cases with much colder and drier than average mid-levels due to extra-tropical intrusions (e.g., Figure 7a). However, these cases were too few in number to trigger a significant result in the hypothesis testing.

Barnes and Sieckman (1984) determined that their fast moving squall lines were shearperpendicular and the slow moving, shear-parallel. The shear-perpendicular mode of organization and the lower $700-\mathrm{hPa} \theta_{\mathrm{e}}$ suggests squall lines that formed near the AEJ axis where most of the intense convective systems in this study and in MT06 occurred. The conditions likely to produce shear-parallel convective systems are most likely to be found south of the surface baroclinic zone, where Figure 5 shows a number of cases did occur. Convective systems in all modes of organization can develop intense convection (Rogash and Racy 2002; Cheng 2005a, b; Parker 2007). Hence, the propagation speed and value of the $700-\mathrm{hPa} \theta_{\mathrm{e}}$ are not reliable predictors of convective intensity, but can suggest mode of organization. The lack of significant results for $700 \mathrm{hPa} \theta_{\mathrm{e}}$ and for the metrics involving minimum $\theta_{\mathrm{e}}$ can be attributed to the same reason as the precipitable water result: overwhelming numbers in areas with similarly dry mid-levels. 
The analysis of equatorial waves, optical depth imagery, and AEW activity added useful but limited insight into intensity prediction. The intra-seasonal variability of intense and nonintense convective system development is similar, particularly when the effect of mid-latitude troughs on non-intense cases disappears after the WAM jump. An increase of all case types can be expected when 200 -hPa northerly wind anomalies due to equatorial Kelvin-like waves occur. Fewer than $25 \%$ of intense cases occurred in environments with detectable dust loads, although this was true of the non-intense cases as well. These results are not directly comparable to INDOEX in which there was a lack of convective activity in a sufficiently humid environment. The detectable dust loads tended to occur in areas that maps of $925-\mathrm{hPa}$ vector winds (not shown) depicted weak southerly to northerly flow. Such environments would have shallow to non-existent monsoon layers. We cannot say whether Saharan aerosol impacted our cases negatively as much as we can say that it designates areas that are unlikely to be favorable to convective development because of insufficient low-level moist advection.

Although AEWs can also enhance low-level moist advection, fewer than half of our cases could be directly associated with AEWs. Because of the difficulty of associating snapshots of individual convective systems with AEW troughs, the percentages in Figure 6 should be considered conservative. However, our general distinctions among case types, time, and location are consistent with the seasonal cycle and the observations of Rowell and Milford (1993). Because propagation speed cannot account for the smaller proportion of intense cases associated with AEWs, we propose that is tied to the energetics of AEWs. In Hsieh and Cook (2007), the barotropic conversions of zonal to eddy available potential energy by an AEW affect the lowlevel vertical shear, depending on the location of the convection relative to the AEJ and the distance to the AEW. North of the AEJ, the barotropic conversion is stronger, and vertical wind 
shear can be significantly reduced. South of the AEJ, the barotropic conversion is weaker thus the change in wind shear minimal. For convection close enough to the AEW trough to be dynamically coupled, the eddies involved in the barotropic conversion may deposit some eddy energy back into other parts of the zonal flow, potentially increasing the vertical wind shear in the vicinity of the convection. Because more intense cases are observed poleward of the AEJ (this study and MT06), the reduction of wind shear by strong barotropic conversions is the most likely general explanation for the lower proportion of intense cases associated with AEWs. Dynamic coupling could contribute to a small proportion of intense cases occurring within 200 $\mathrm{km}$ of an AEW and would increase the difficulty of assessing the likelihood that intense vs. nonintense convective systems will occur within $200 \mathrm{~km}$ of AEW troughs.

In the controllable environment of a model, simulations that generate higher surface $\theta_{\mathrm{e}}$, and thus more CAPE, can usually be expected to generate stronger convection (e.g., Crook 1996; McCaul et al. 2005). Even cloud-resolving models simplify or are not able to account for the multiple small-scale effects such as waterloading that affect how CAPE will be utilized by natural convective systems. In Figure 10, a scatter plot of surface $\theta_{\mathrm{e}}$ vs. low-level shear, both insitu sounding data series exhibit substantial scatter and overlap. Substituting CAPE for surface $\theta_{\mathrm{e}}$ in Figure 10 results in similar scatter patterns. There are relatively few intense cases in environments combining shears greater than $-2.5 \times 10^{-3} \mathrm{~s}^{-1}$ and surface $\theta_{\mathrm{e}}$ less than $345 \mathrm{~K}$, but there is also a non-negligible number of non-intense cases in environments with shears less than $-5.0 \times 10^{-3} \mathrm{~s}^{-1}$ and surface $\theta_{\mathrm{e}}$ greater than $360 \mathrm{~K}$. Case intensity was not consistently proportional to surface $\theta_{\mathrm{e}}$, to low-level shear, or to the combination, making them unreliable for directly predicting intensity in an uncontrolled operational framework. 


\section{Summary}

We used EMCWF operational analysis, in-situ sounding data, and MODIS aerosol optical depth imagery to diagnose the environments of intense convective systems during 2003 in West Africa. We extracted convective system cases from TMI data at $85-\mathrm{GHz}$, identifying convective systems from contiguous image pixels $255 \mathrm{~K}$ or less with an area at least $64 \mathrm{~km}^{2}$. These convective systems were classified as intense (minimum PCT $\leq 135 \mathrm{~K}$ ) or non-intense (minimum PCT $>135 \mathrm{~K}$ ). The intense cases were further partitioned by their estimated elapsed time of propagation from high terrain $(>500 \mathrm{~m})$. For our local environmental analysis, we matched 168 intense and 152 non-intense cases to soundings taken at 8 sounding sites and constructed soundings from the operational analysis for 2843 non-intense cases close to high terrain and 1907 intense cases throughout the study region. For our regional analysis, we used an additional 10853 non-intense cases.

Hypothesis testing revealed that the speed of the mid-level jet, the magnitude of the lowlevel shear, and the surface $\theta_{\mathrm{e}}$ were significantly greater for the intense cases compared to the non-intense cases for both the in-situ and operational analysis sounding cases. However, the differences between the means tended to be small, less than $3 \mathrm{~K}$ for surface $\theta_{\mathrm{e}}$. Hypothesis testing of a series of commonly used intensity prediction metrics resulted in significant results only for low-level metrics such as CAPE and not for any of the mid-level metrics such as 700$\mathrm{hPa} \theta_{\mathrm{e}}$ or upper-level metrics such as TEJ speed. Plotting surface $\theta_{\mathrm{e}}$ vs. low-level shear for insitu intense and non-intense cases on the same scatter plots revealed significant scatter and overlap. None of the environmental variables or intensity metrics by themselves or in combination appeared to be reliable direct predictors of intensity in an operational framework. 
In the regional scale analysis, the majority of intense convective systems occurred in the surface baroclinic zone where surface $\theta_{\mathrm{e}}$ exceeded $344 \mathrm{~K}$ and $700-\mathrm{hPa}$ zonal wind speeds were less than $-6 \mathrm{~ms}^{-1}$. The proportion of intense cases associated with AEWs was almost half the proportion of non-intense cases at any of the AEW distance criteria that we set (e.g., $10 \%$ vs. $20 \%$ at 1 -AEW trough length). The relationships to AEWs were consistent with the seasonal movement of the WAM, regional differences in topography, and, we propose, to AEW energetics. The relationship of our cases to Saharan aerosol was consistent with the seasonal movement of the surface baroclinic zone and intertropical front. Fewer than $25 \%$ of our cases occurred in environments with detectable dust loads. The seasonal mean cumulative frequency distributions for both non-intense and intense cases were similar. The far-intense cases were to the left of the intense mean, and terrain intense cases were almost the same distance to the right. Compared to the seasonal mean, more June cases occurred in dusty environments and fewer in August and September.

Low-level shear, surface $\theta_{\mathfrak{e}}$, Saharan aerosol outbreaks, and the phases of synoptic-scale to equatorial-scale waves appear more reliable as discriminators between convective and fair weather environments rather than direct predictors of intensity. Mapping the surface baroclinic zone (e.g., Figure 5) can add additional value by designating areas within convective environments where intense convective systems are more likely to occur. To go beyond forecasting general probabilities to developing a warning system would be a substantial challenge for a region that now has few surface radar observing systems. The evolving convective-scale warn-on-forecast system in the U.S. depends on the assimilation of the observations from a relatively dense surface radar network (Stensrud et al. 2009). Space-based radar observations with high temporal resolution such as the proposed 3-hourly NASA Global 
Precipitation Mission constellation could greatly assist in improving severe weather forecasting in this region.

\section{Acknowledgments}

We obtained the ECMWF operational analysis from the NCAR Research Data Archive, the in-situ sounding data from the University of Wyoming atmospheric sounding web site (http://weather.uwyo.edu/upperair/sounding.html), the TRMM 1B11 brightness temperature product from the NASA-GSFC Distributed Active Archive (http://mirador.gsfc.nasa.gov), and the MODIS aerosol optical depth product from the NASA-GSFC Level 2 and Atmosphere Archive and Distribution System (http://ladsweb.nascom.nasa.gov/). R. Hucek assisted with the processing and interpretation of the MODIS product. G. Berry and A. Srock provided code and advice for the AEW analysis. We had important conversations with P. Roundy, J.-S. Hsieh, R. Kahn, S. Braun, and M. Weisman. C. Thorncroft provided comments on the thesis from which this manuscript is derived. We had support from NASA Precipitation Measuring Mission grant NNX07AD45G and NSF grant ATM0538164. 


\section{References}

Ackerman, A. S., B. Toon, D. E. Stevens, A. J. Heymsfield, V. Ramanathan, and E. J. Welton, 2000: Reduction of tropical cloudiness by soot. Science, 288, 1042-1047.

Albrecht, B. A., 1989: Aerosols, cloud microphysics, and fractional cloudiness. Science, 245, $1227-1230$.

Alexander, G. D., and G. S. Young, 1992: The relationship between EMEX mesoscale precipitation feature properties and their environmental characteristics. Mon. Wea. Rev., 120, 554-564.

Barnes, G. M., and K. Sieckman, 1984: The environment of fast- and slow-moving tropical mesoscale convective cloud lines. Mon. Wea. Rev., 112, 1782-1794.

Berry, G., C. Thorncroft, and T. Hewson, 2007: African easterly waves during 2004 -Analysis using objective techniques. Mon. Wea. Rev., 135, 1251-1267.

Burpee, R. W., 1972: The origin and structure of easterly waves in the lower troposphere of North Africa. J. Atmos. Sci., 29, 77-90.

Carlson, T. N., and J. M. Prospero, 1972: The large-scale movement of Saharan air outbreaks over the northern equatorial Atlantic. J. Appl. Meteor., 11, 283-297.

Cecil, D. J., S. J. Goodman, D. J. Boccippio, E. J. Zipser, and S. W. Nesbitt, 2005: Three years of TRMM precipitation features. Part I: Radar, radiometric, and lightning characteristics. Mon. Wea. Rev., 133, 543-566.

Charlson, R. J., J. Langner, H. Rodhe, C. B. Leovy, and S. G. Warren, 1991: Perturbation of the Northern Hemisphere radiative balance by backscattering from anthropogenic sulfate aerosols. Tellus, 43, 152-163. 
Cheng, A., 2005a: Organization of mesoscale convective systems: 1 . Numerical experiments. $J$. Geophys. Res., 110, doi:10.1029/2004JD005444.

— , 2005b: Organization of mesoscale convective systems: 2. Linear theory. J. Geophys. Res., 110, doi: $10.1029 / 2004 J \mathrm{D} 005450$.

Coakley, J. A., and R. D. Cess, 1985: Response of the NCAR Community Climate Model to the radiative forcing by the naturally-occurring tropospheric aerosol. J. Atmos. Sci., 42, 16771692.

Coakley, J. A., Jr., R. D. Cess, and F. B. Yurevich, 1983: The effect of tropospheric aerosols on the earth's radiation budget: A parameterization for climate models. J. Atmos. Sci., 40, 116138.

Crook, N. A., 1996: Sensitivity of moist convection forced by boundary layer processes to lowlevel thermodynamic fields. Mon. Wea. Rev., 124, 1767-1786.

Dai, A., 2001: Global precipitation and thunderstorm frequencies. Part II: Diurnal variations. $J$. Climate, 14, 1112-1128.

Fan, J., R. Zhang, W.-K. Tao, and K. I. Mohr, 2008: Effects of aerosol optical properties on deep convective clouds and radiative forcing. J. Geophys. Res., 113, doi:10.1029/2007JD009257.

Flamant, C., and Coauthors, 2007: Airborne observations of the impact of a convective system on the planetary boundary layer thermodynamics and aerosol distribution in the inter-tropical discontinuity region of the West African monsoon. Quart. J. Roy. Meteor. Soc., 133, 11751189.

Fovell, R. G., and Y. Ogura, 1989: Effect of vertical wind shear on numerically simulated multicell storm structure. J. Atmos. Sci., 46, 3144-3176.

Frank, W. M., 1978: The life cycles of GATE convective systems. J. Atmos. Sci., 35, 1256-1264. 
Hagos, S. M., and K. H. Cook, 2007: Dynamics of the West African Monsoon jump. J. Climate, 20, 5264-5284.

Hastenrath, S., 1991: Climate Dynamics of the Tropics. Kluwer, 488 pp.

Hodges, K. I., and C. D. Thorncroft, 1997: Distribution and statistics of African mesoscale convective weather systems based on the ISCCP Meteosat imagery. Mon. Wea. Rev., 125, 2821-2837.

Hopsch, S. B., C. D. Thorncroft, K. Hodges, and A. Aiyyer, 2007: West African storm tracks and their relationship to Atlantic tropical cyclones. J. Climate, 20, 2468-2483.

Houze, R. A., Jr., 2004: Mesoscale convective systems. Reviews of Geophysics, 42, doi:10.1029/2004RG000150.

Hsieh, J. S., and K. H. Cook, 2007: A study of the energetics of African easterly waves using a regional climate model. J. Atmos. Sci., 64, 421-440.

Hsu, N. C., S.-C. Tsay, M. D. King, and J. R. Herman, 2006: Deep Blue retrievals of Asian aerosol properties during ACE-Asia. IEEE Transactions on Geoscience and Remote Sensing, 44, 3180-3195.

James, R. P., J. M. Fritsch, and P. M. Markowski, 2005: Environmental distinctions between cellular and slabular convective lines. Mon. Wea. Rev., 133, 2669-2691.

Jankowiak, I., and D. Tanré, 1992: Satellite climatology of Saharan dust outbreaks: Method and preliminary results. J. Climate, 5, 646-656.

Johnson, R. H., S. L. Aves, P. E. Ciesielski, and T. D. Keenan, 2005: Organization of oceanic convection during the onset of the 1998 East Asian summer monsoon. Mon. Wea. Rev., 133, 131-148. 
Karyampudi, V. M., and Coauthors, 1999: Validation of the Saharan dust plume conceptual model using lidar, Meteosat, and ECMWF data. Bull. Amer. Meteor. Soc., 80, 1045-1075.

Lafore, J.-P., and M. W. Moncrieff, 1989: A numerical investigation of the organization and interaction of the convective and stratiform regions of tropical squall lines. J. Atmos. Sci., 46, $521-544$.

LeMone, M. A., E. J. Zipser, and S. B. Trie, 1998: The role of environmental shear and thermodynamic conditions in determining the structure and evolution of mesoscale convective systems during TOGA COARE. J. Atmos. Sci., 55, 3493-3518.

Levinson, D. H., and A. M. Waple, 2004: State of the climate in 2003. Bull. Amer. Meteor. Soc., 85,881 .

Lucas, C., E. J. Zipser, and B. S. Ferrier, 2000: Sensitivity of tropical West Pacific oceanic squall lines to tropospheric wind and moisture profiles. J. Atmos. Sci., 57, 2351-2373.

M'bourou, G. N., J. J. Bertrand, and S. E. Nicholson, 1997: The diurnal and seasonal cycles of wind-borne dust over Africa north of the equator. J. Appl. Meteor., 36, 868-882.

McCaul, E. W., Jr., C. Cohen, and C. Kirkpatrick, 2005: The sensitivity of simulated storm structure, intensity, and precipitation efficiency to environmental temperature. Mon. Wea. Rev., 133, 3015-3037.

McGaughey, G. R., E. J. Zipser, R. W. Spencer, and R. E. Hood, 1996: High resolution passive microwave observations of convective systems over the tropical Pacific Ocean. J. Appl. Meteor., 35, 1921-1947.

Mohr, K. I., 2004: Interannual, monthly, and regional variability in the wet season diurnal cycle of precipitation in Sub-Saharan Africa. J. Climate, 17, 2441-2453. 
Mohr, K. I., and E. J. Zipser, 1996: Mesoscale convective systems defined by their $85 \mathrm{GHz}$ ice scattering signature: Size and intensity comparison over tropical oceans and continents. Mon. Wea. Rev., 124, 2417-2437.

Mohr, K. I., and C. Thorncroft, 2006: The distribution of intense convective systems in West Africa and their relationship to the African easterly jet. Quart. J. Roy. Meteor. Soc., 132, 163176.

Mohr, K. I., J. Molinari, and C. D. Thorncroft, 2009: The interannual stability of cumulative frequency distributions for convective system size and intensity. J. Climate, 19, 5218-5231.

Mounier, F., and S. Janicot, 2004: Evidence of two independent modes of convection at intraseasonal timescale in the West African summer monsoon. Geophys. Res. Lett., 31, L16116, doi:16110.11029/12004GL020665.

Mounier, F., S. Janicot, and G. N. Kiladis, 2008: The West African monsoon dynamics. Part III: The quasi-biweekly zonal dipole. J. Climate, 21, 1911-1928.

Nesbitt, S. W., E. J. Zipser, and D. J. Cecil, 2000: A census of precipitation features in the Tropics using TRMM: Radar, ice scattering, and lightning observations. J. Climate, 13, 40874106.

Nicholson, S. E., A. I. Barcilon, M. Challa, and J. Baum, 2007: Wave activity on the tropical easterly jet. J. Atmos. Sci., 64, 2756-2763.

Parker, D. J., C. D. Thorncroft, R. Burton, and A. Diongue, 2005: Analysis of the African easterly jet using aircraft observations from the JET2000 experiment. Quart. J. Roy. Meteor. Soc., 131, 1461-1482.

Parker, M. D., 2007: Simulated convective lines with parallel stratiform precipitation. Part I: An archetype for convection in along-line shear. J. Atmos. Sci., 64, 267-288. 
Ramanathan, V., P. J. Crutzen, J. T. Kiehl, and D. Rosenfeld, 2001a: Aerosol, climate and the hydrological cycle. Science, 294, 2119-2124.

Ramanathan, V., and Coauthors, 2001b: Indian Ocean Experiment: An integrated analysis of the climate forcing and effects of the great Indo-Asian haze. J. Geophys. Res., 106, 28371-28398.

Reed, R. J., 1980: The structure and behaviour of easterly waves over West Africa and the Atlantic. Quart. J. Roy. Meteor. Soc., 106, 57-71.

Reed, R. J., D. C. Norquist, and E. E. Recker, 1977: The structure and properties of African wave disturbances as observed during Phase III of GATE. Mon. Wea. Rev., 105, 334-342.

Robe, F. R., and K. A. Emanuel, 2001: The effect of vertical wind shear on radiative-convective equilibrium states. J. Atmos. Sci., 58, 1427-1445.

Roca, R., J.-P. Lafore, C. Piriou, and J.-L. Redelsperger, 2005: Extratropical dry-air intrusions into the West African monsoon midtroposphere: An important factor for the convective activity over the Sahel. J. Atmos. Sci., 62, 390-407.

Rogash, J. A., and J. Racy, 2002: Some meteorological characteristics of significant tornado events occurring in proximity to flash flooding. Wea. Forecasting, 17, 155-159.

Rosenfeld, D., 2000: Suppression of rain and snow by urban and industrial air pollution. Science, 287, 1793-1796.

Rosenfeld, D., and I. M. Lensky, 1998: Satellite-based insights into precipitation formation processes in continental and maritime convective clouds. Bull. Amer. Meteor. Soc., 79, 24572476.

Rotunno, R., J. B. Klemp, and M. L. Weisman, 1988: A theory for strong, long-lived squall lines. J. Atmos. Sci., 45, 463-485. 
Rowell, D. P., and J. R. Milford, 1993: On the generation of African squall lines. J. Climate, 6, $1181-1193$.

Spencer, R. W., H. M. Goodman, and R. E. Hood, 1989: Precipitation retrieval over land and ocean with the SSM/I: Identification and characteristics of the scattering signal. J. Atmos. Oceanic Technol., 6, 254-273.

Stensrud, D. J., and Coauthors, 2009: Convective-scale warn-on-forecast system. Bull. Amer. Meteor. Soc., 90, 1487-1499.

Sultan, B., and S. Janicot, 2003: The West African monsoon dynamics. Part II: The "preonset" and "onset" of the summer monsoon. J. Climate, 16, 3407-3427.

Sultan, B., S. Janicot, and A. Diedhiou, 2003: The West African monsoon dynamics. Part I: Documentation of intraseasonal variability. J. Climate, 16, 3389-3406.

Takemi, T., 2006: Impacts of moisture profile on the evolution and organization of midlatitude squall lines under various shear conditions. Atmos. Res., 82, 37-54.

$\ldots$, 2007a: A sensitivity of squall-line intensity to environmental static stability under various shear and moisture conditions. Atmos. Res., 84, 374-389.

_ 2007b: Environmental stability control of the intensity of squall lines under low-level shear conditions. J. Geophys. Res., 112, doi:10.1029/2007JD008793.

Toracinta, E. R., D. J. Cecil, E. J. Zipser, and S. W. Nesbitt, 2002: Radar, passive microwave, and lightning characteristics of precipitating systems in the Tropics. Mon. Wea. Rev., 130, 802-824.

Tsakraklides, G., and J. L. Evans, 2003: Global and regional diurnal variations of organized convection. J. Climate, 16, 1562-1572. 
Twomey, S., 1977: The influence of pollution on the shortwave albedo of clouds. J. Atmos. Sci., 34, 1149- 1152.

Weisman, M. L., and J. B. Klemp, 1982: The dependence of numerically simulated convective storms on vertical wind shear and buoyancy. Mon. Wea. Rev., 110, 504-520.

_ 1984: The structure and classification of numerically simulated convective storms in directionally varying wind shears. Mon. Wea. Rev., 112, 2479-2498.

Weisman, M. L., and R. Rotunno, 2004: "A Theory for Strong Long-Lived Squall Lines" revisited. J. Atmos. Sci., 61, 361-382.

Williams, E. R., and S. Stanfill, 2002: The physical origin of the land-ocean contrast in lightning activity. Comp. Rendus Phys., 3, 1277-1292.

Zhang, G. J., 2003: Diurnal cycle of convection at the ARM SGP Site: Role of large-scale forcing, surface fluxes, and convective inhibition. 13th Atmospheric Radiation Measurement Science Team Meeting, Broomfield, CO, www.arm.gov/publications/proceedings.stm.

Zipser, E. J., D. J. Cecil, C. Liu, S. W. Nesbitt, and D. P. Yorty, 2006: Where are the most intense thunderstorms on Earth? Bull. Amer. Meteor. Soc., 87, 1057-1071. 


\section{List of Figures}

Figure 1. West Africa with the study area $\left(3^{\circ}-21^{\circ} \mathrm{N}, 17^{\circ} \mathrm{W}-30^{\circ} \mathrm{E}\right)$ outlined. Sub-divisions of the study area used in the regional-scale analysis are labeled with large print. Locations of the 8 sounding sites used in the in-situ sounding analysis are indicated by a black diamond and labeled with small print.

Figure 2. Example comparison of a) an in-situ sounding from Douala (64910) for 18 May at $12 Z$ and b) a sounding constructed from ECMWF operational analysis (EOA-Snd) for the corresponding model gridcell and time.

Figure 3. Histograms of surface $\theta_{\mathrm{e}}$ for a) all non-intense and intense cases, b) for the intense EOA-sounding cases, classified by terrain. Histogram of mid-level wind speed in c) depicts AEJ wind speed for in-situ sounding cases and 700-hPa wind speed for EOA-sounding cases.

Figure 4. Cumulative frequency distributions of pseudo-adiabatic CAPE $\left(\mathrm{J} \mathrm{kg}^{-1}\right)$ for the in-situ cases: far-intense (grey with squares), near-terrain and terrain-intense (black with circles), and non-intense (black with triangles).

Figure 5. Contour plots for 21-29 Jul of 700-hPa zonal winds ( $\mathrm{m} \mathrm{s}^{-1}$, left panels) and surface $\theta_{\mathrm{e}}$ (K, right panels). Gray shades indicate winds less than $-6 \mathrm{~m} \mathrm{~s}^{-1}$ and $\theta_{\mathrm{e}}$ greater than $344 \mathrm{~K}$. Panels a) and b) have intense cases overlaid. Panels c) and d) have non-intense cases overlaid. Farintense cases are plotted as triangles, near-terrain and terrain-intense cases as squares, nonintense cases as circles.

Figure 6. Cases meeting the 4 distance criteria for AEWs, a) number of cases by regional subdivision for the wet season, b) percentage of seasonal total by subdivision, obtained by 
dividing the number at each distance in a) by each subdivision's total cases in the legend of b); c) percentage of seasonal total by case type, obtained from case type totals in Table 1 ; d) percentage of cases within 1-AEW trough length by subdivision and by month. Case counts used in a) and b) reflect differences in size between the northern and the southern subdivisions.

Figure 7. Contour plots of aerosol optical depth in optical depth units $\left(\mathrm{kg} \mathrm{m}^{3} \mathrm{~kg}^{-1} \mathrm{~m}^{-3}\right)$ for a) 23 May, b) 23 Jun, c) 24 Jul, d) 23 Aug. Gray shades indicate detectable dust over land. Areas in white are either over ocean or below instrument sensitivity over land. Dotted areas denote data dropouts and gaps between Aqua overflights. Intense and non-intense cases for each day are overplotted with the same symbol legend as Figure 5.

Figure 8. Cumulative frequency distributions of aerosol optical depth for each month and the seasonal mean for a) non-intense cases, b) all intense cases, c) near- and terrain-intense cases, d) far-intense cases. In all panels, the seasonal mean is a solid gray line, and the months are plotted in black: May (dotted), June (long, open dashes), July (dash-dot), August (short dashes), September (solid line). Because some bins contain few cases, the curves are not smooth.

Figure 9. Hovmöller plots for the latitude band $6.75^{\circ} \mathrm{N}-14.625^{\circ} \mathrm{N}$ for a) $200-\mathrm{hPa}$ zonal (U) winds with easterly winds shaded, b) $200-\mathrm{hPa}$ meridional (V) winds with northerly winds shaded. In c) time series of the 5-day running mean of daily total convective systems (all case types, solid line) and daily total intense convective systems (dashed line). All panels use the same time scale.

Figure 10. Scatter plot of surface $\theta_{\mathrm{e}}(\mathrm{K})$ vs. low-level shear $\left(\mathrm{s}^{-1}\right)$ for the in-situ intense (black diamond) and non-intense (gray square) cases. 


\section{List of Tables}

Table 1. The four case types used in the analysis. Cases were classified by minimum PCT and proximity to high terrain $(\geq 500 \mathrm{~m})$.

Table 2. Status information of the 8 sounding sites. “\% Completed" represents how many soundings were completed vs. the number that could have been launched. It was calculated by dividing the number of soundings in column 3 by the product of the number of days in the study period (153) and the number of observation times (1 or 2).

Table 3. Summary of thermodynamic variables for in-situ sounding cases. The shear layers for low-level (LL), mid-level (ML), and deep-layer (DL) are defined in Section 2. Values for shear and $\theta_{\mathrm{e}}$ are category means. Minimum PCT is the median value. The first two rows are nonintense cases vs. intense cases, all case types. The third row contains p-values for one-tailed intense vs. non-intense hypothesis tests. Significant results at $\alpha=0.05$ where $\mu_{\text {intense }}>\mu_{\text {non-intense }}$ are in bold. Significant results at $\alpha=0.05$ where $\mu_{\text {intense }}<\mu_{\text {non-intense }}$ are in bold italics. The last three rows compare the intense case types.

Table 4. Summary of thermodynamic variables for EOA-sounding cases. The table layout is similar to Table 3, except that only the low-level (surface to $700-\mathrm{hPa}$ ) shear is reported, and the last row contains p-values for far-intense vs. terrain and near-terrain intense case types. 


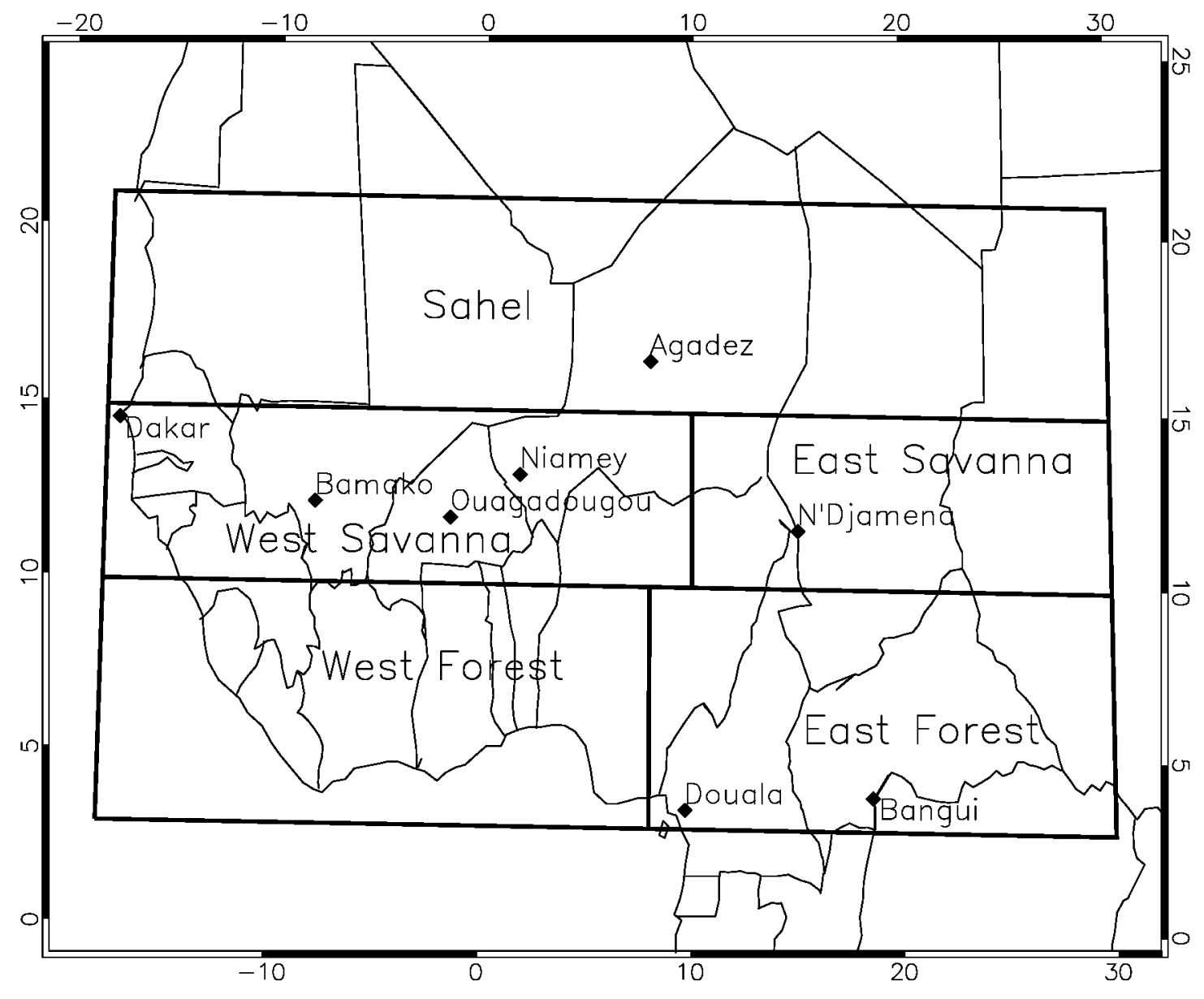

Figure 1. West Africa with the study area $\left(3^{\circ}-21^{\circ} \mathrm{N}, 17^{\circ} \mathrm{W}-30^{\circ} \mathrm{E}\right)$ outlined. Sub-divisions of the study area used in the regional-scale analysis are labeled with large print. Locations of the 8 sounding sites used in the in-situ sounding analysis are indicated by a black diamond and labeled with small print. 


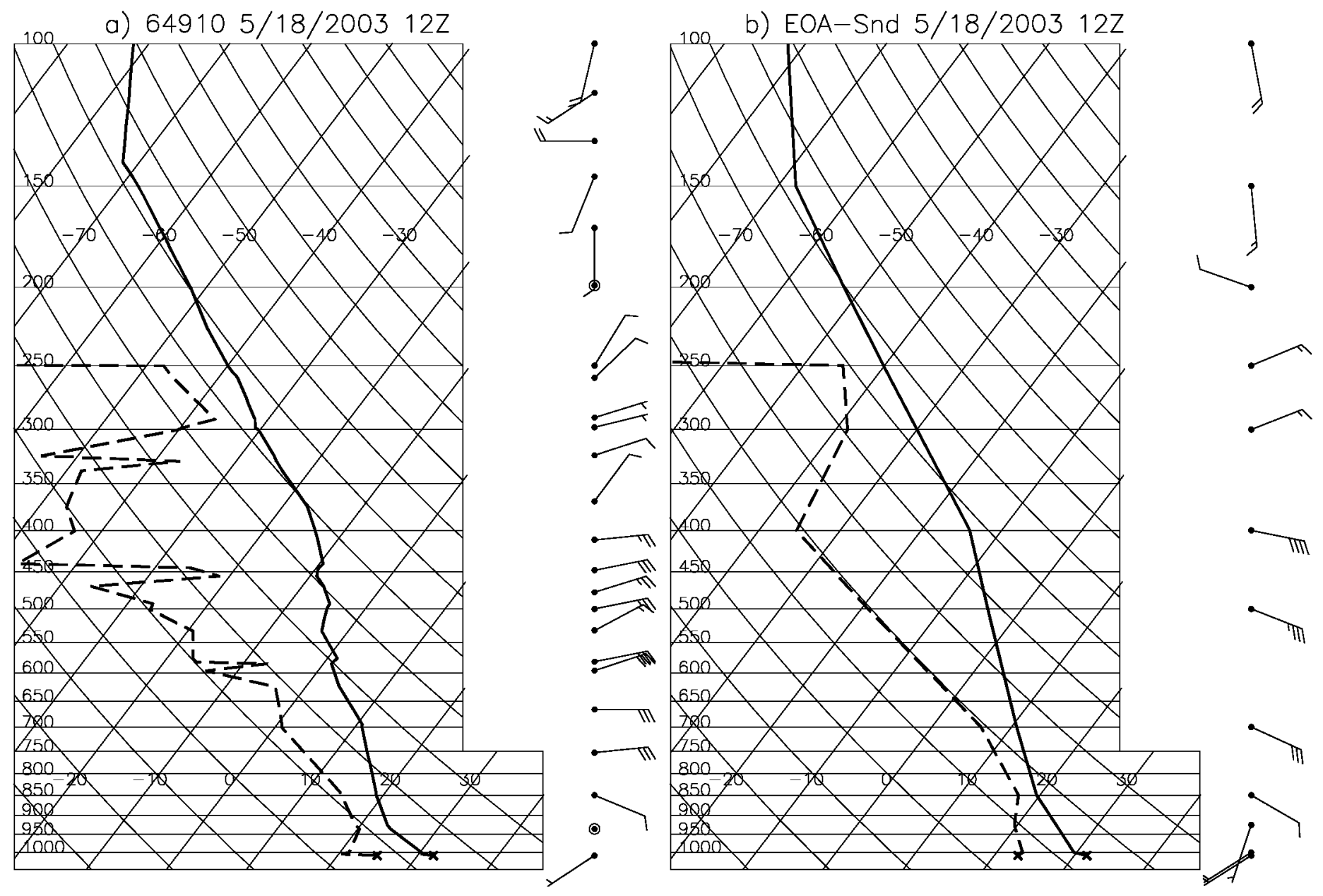

Figure 2. Example comparison of a) an in-situ sounding from Douala (64910) for 18 May at $12 Z$ and b) a sounding constructed from ECMWF operational analysis (EOA-Snd) for the corresponding model gridcell and time. 

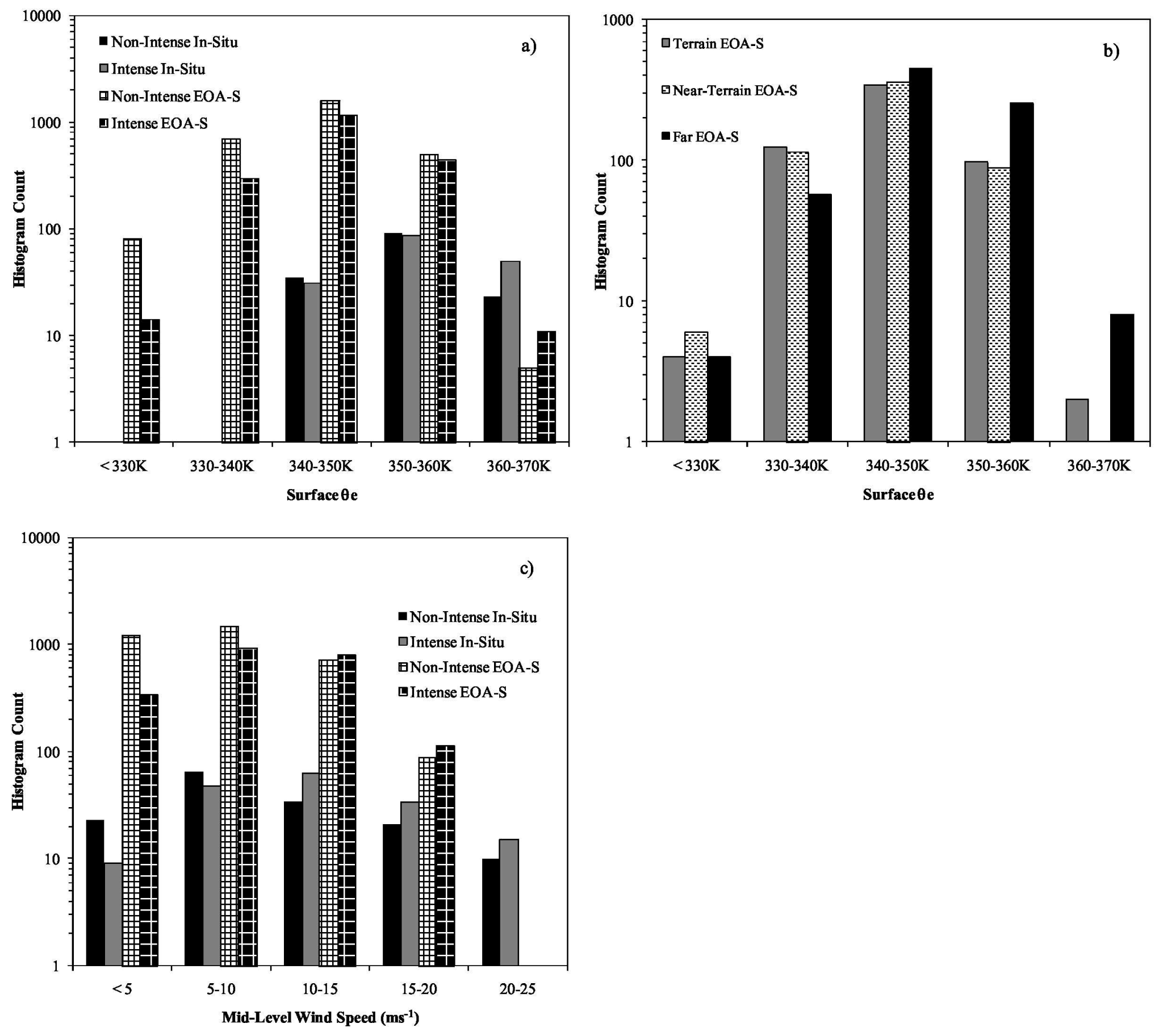

Figure 3. Histograms of surface $\theta_{e}$ for a) all non-intense and intense cases, b) for the intense EOA-sounding cases, classified by terrain. Histogram of mid-level wind speed in c) depicts AEJ wind speed for in-situ sounding cases and 700-hPa wind speed for EOA-sounding cases. 


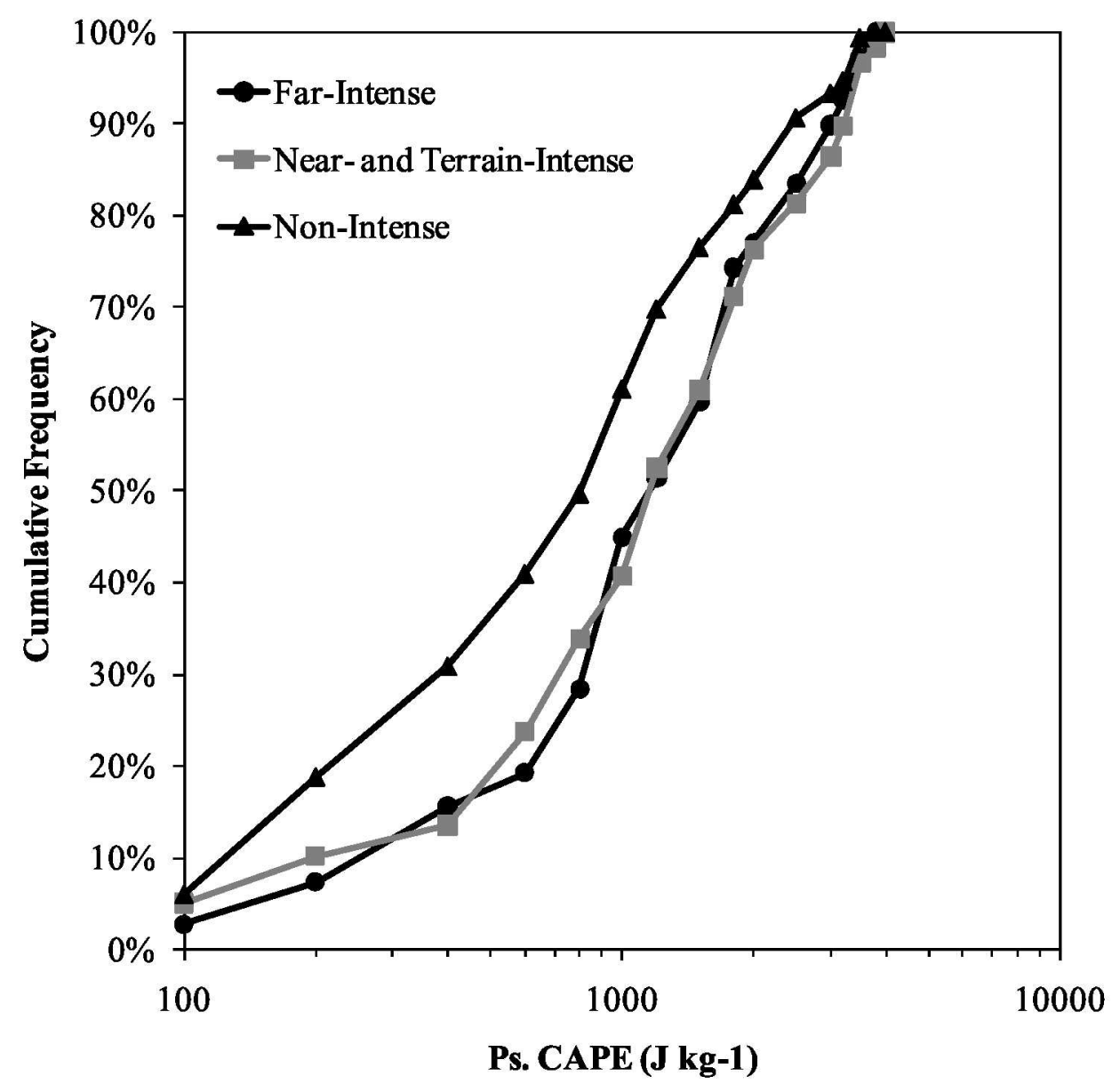

Figure 4. Cumulative frequency distributions of pseudo-adiabatic CAPE $\left(\mathrm{J} \mathrm{kg}^{-1}\right)$ for the in-situ cases: far-intense (grey with squares), near-terrain and terrain-intense (black with circles), and non-intense (black with triangles). 
a) $700 \mathrm{hPa}$ U-Wind $\left(\mathrm{ms}^{-1}\right)$ and Intense Cases $7 / 21-7 / 29 / 2003$

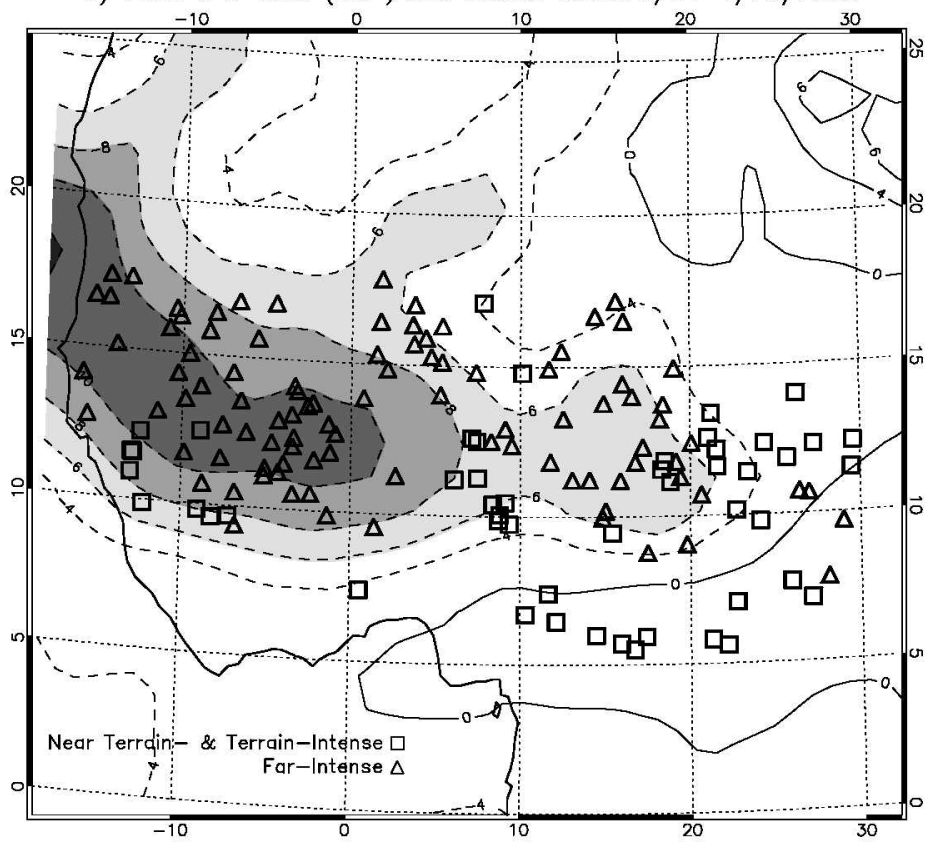

c) Surface $\theta_{e}(K)$ and Intense Cases $7 / 21-7 / 29 / 2003$

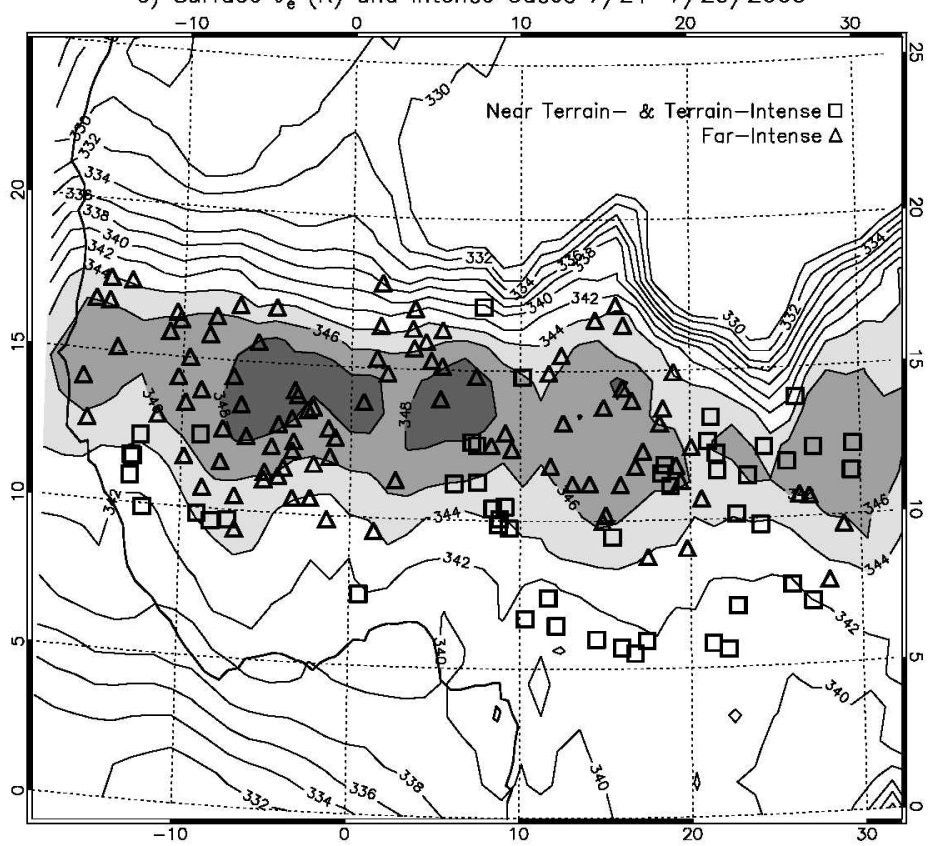

b) $700 \mathrm{hPa} \mathrm{U}-$ Wind $\left(\mathrm{ms}^{-1}\right)$ and Non-Intense Cases $7 / 21-7 / 29 / 2003$

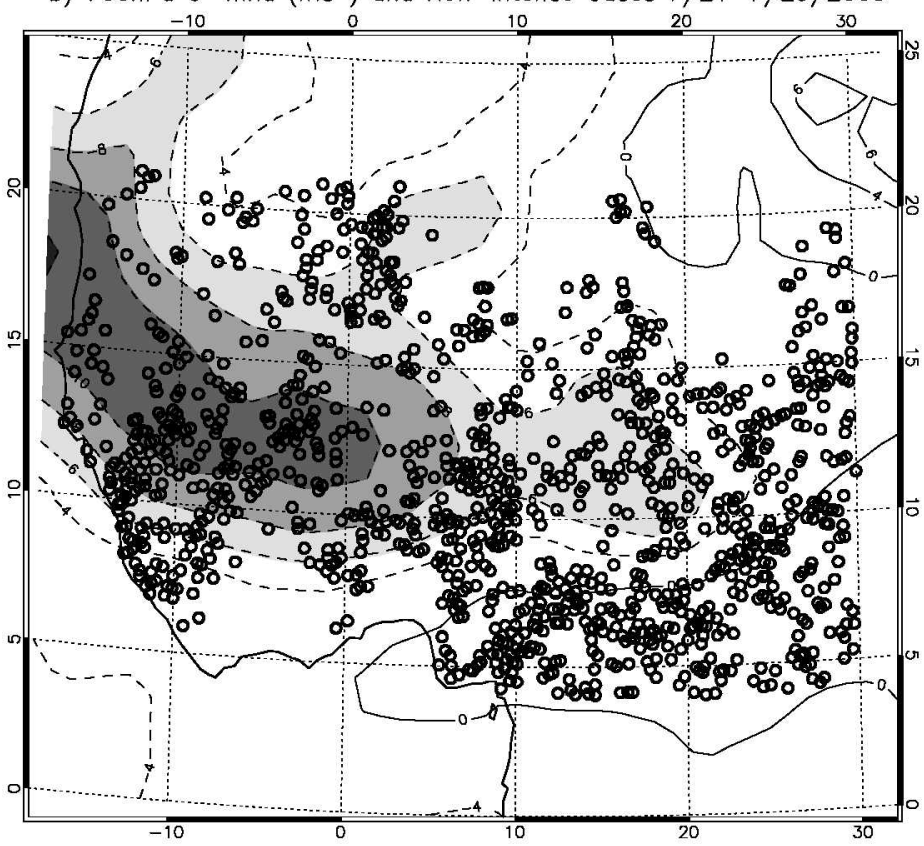

d) Surface $\theta_{e}(K)$ and Non-Intense Cases 7/21-7/29/2003

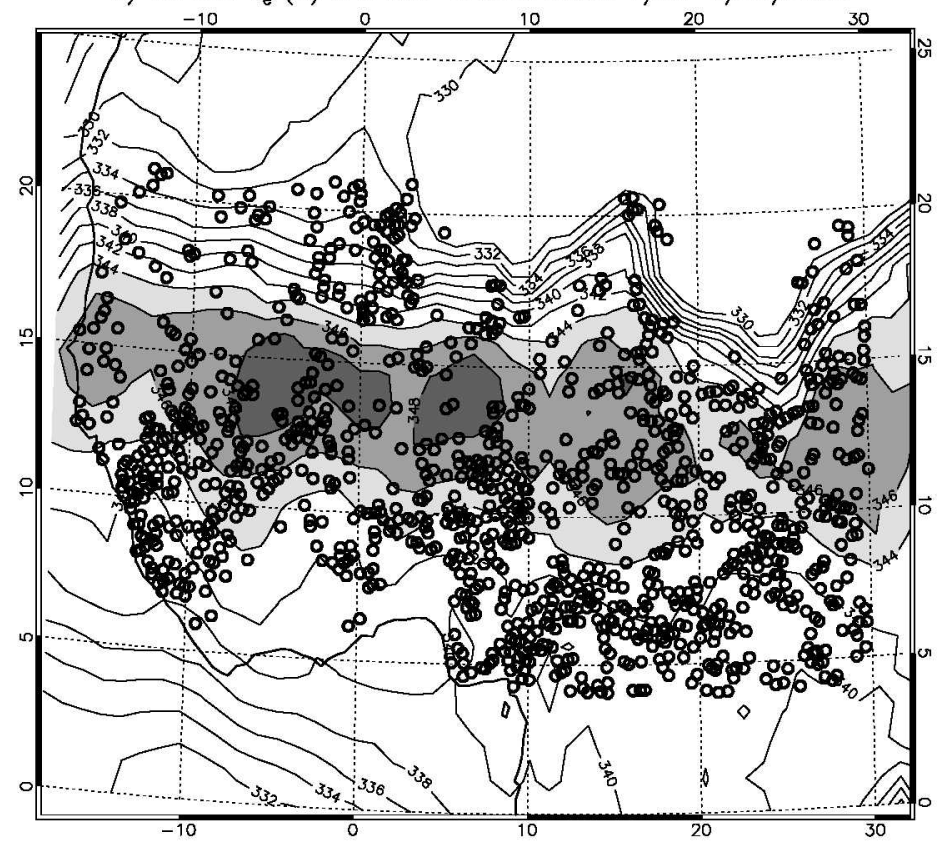

Figure 5. Contour plots for 21-29 Jul of 700-hPa zonal winds ( $\mathrm{m} \mathrm{s}^{-1}$, left panels) and surface $\theta_{\mathrm{e}}$ (K, right panels). Gray shades indicate winds less than $-6 \mathrm{~m} \mathrm{~s}^{-1}$ and $\theta_{\text {e }}$ greater than $344 \mathrm{~K}$. Panels a) and b) have intense cases overlaid. Panels c) and d) have non-intense cases overlaid. Farintense cases are plotted as triangles, near-terrain and terrain-intense cases as squares, nonintense cases as circles. 

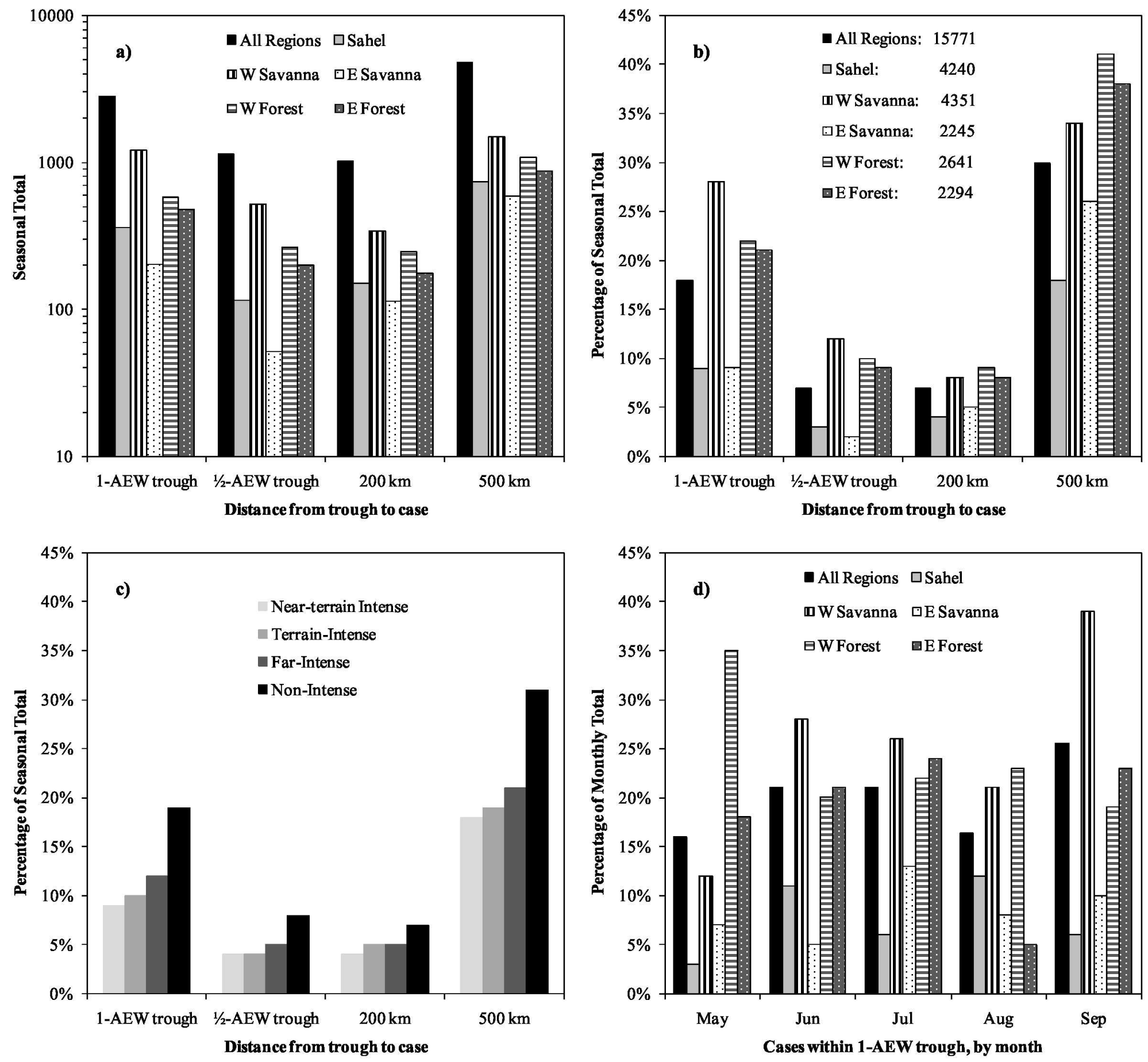

Figure 6. Cases meeting the 4 distance criteria for AEWs, a) number of cases by regional subdivision for the wet season, b) percentage of seasonal total by subdivision, obtained by dividing the number at each distance in a) by each subdivision's total cases in the legend of b); c) percentage of seasonal total by case type, obtained from case type totals in Table 1; d) percentage of cases within 1-AEW trough length by subdivision and by month. Case counts used in a) and b) reflect differences in size between the northern and the southern subdivisions. 
a) Aerosol Optical Depth for $5 / 23 / 2003$

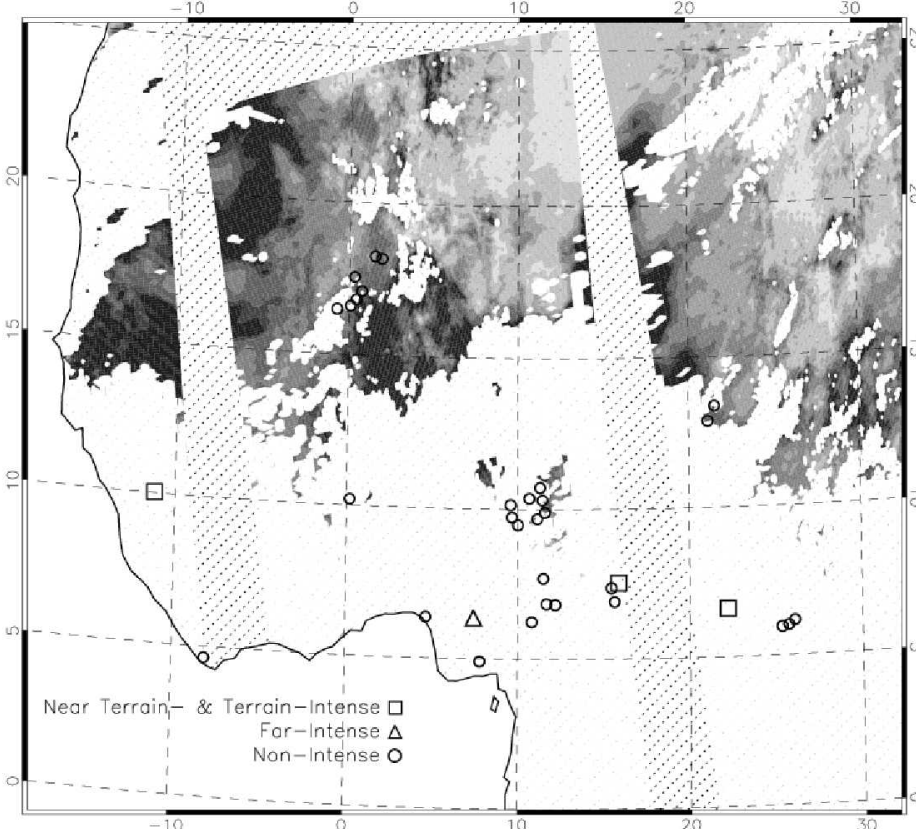

Optical Depth $\left(\mathrm{kgm}^{3} \mathrm{~kg}^{-1} \mathrm{~m}^{-3}\right)$

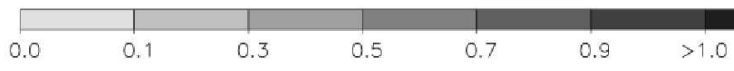

c) Aerosol Optical Depth for $7 / 24 / 2003$

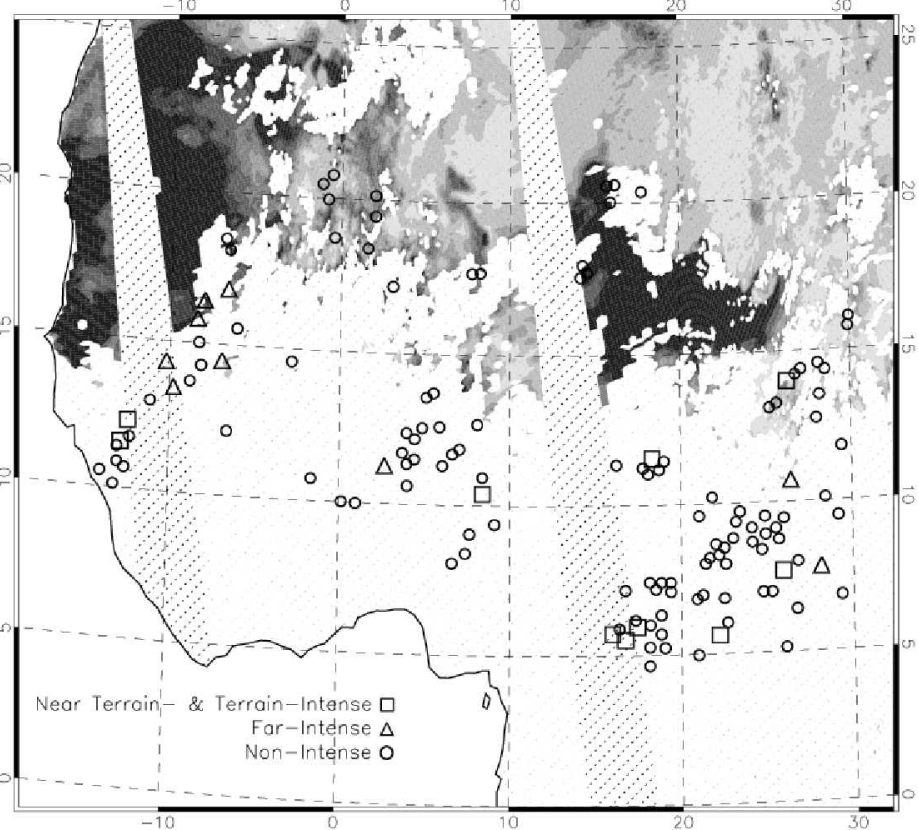

Optical Depth $\left(\mathrm{kgm}^{3} \mathrm{~kg}^{-1} \mathrm{~m}^{-3}\right)$

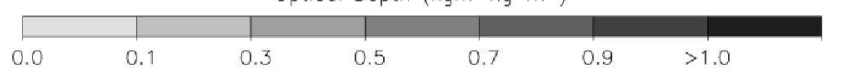

b) Aerosol Optical Depth for $6 / 23 / 2003$

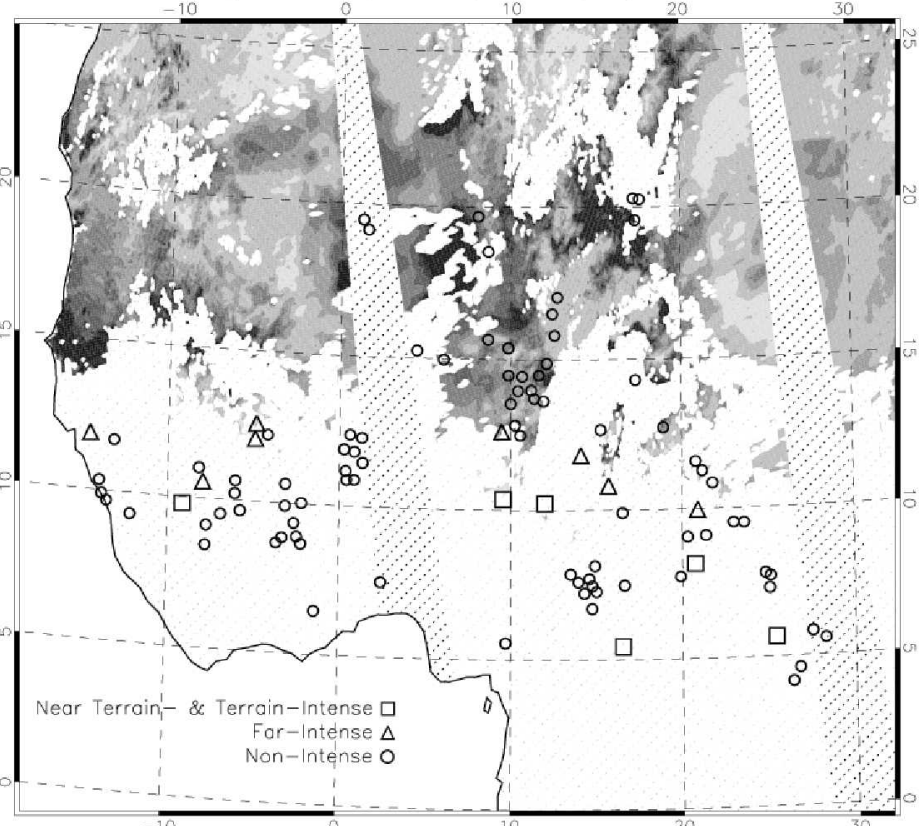

Optical Depth $\left(\mathrm{kgm}^{3} \mathrm{~kg}^{-1} \mathrm{~m}^{-3}\right)$

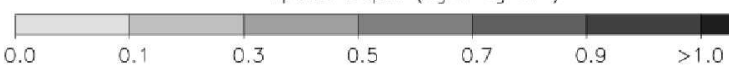

d) Aerosol Optical Depth for $8 / 23 / 2003$

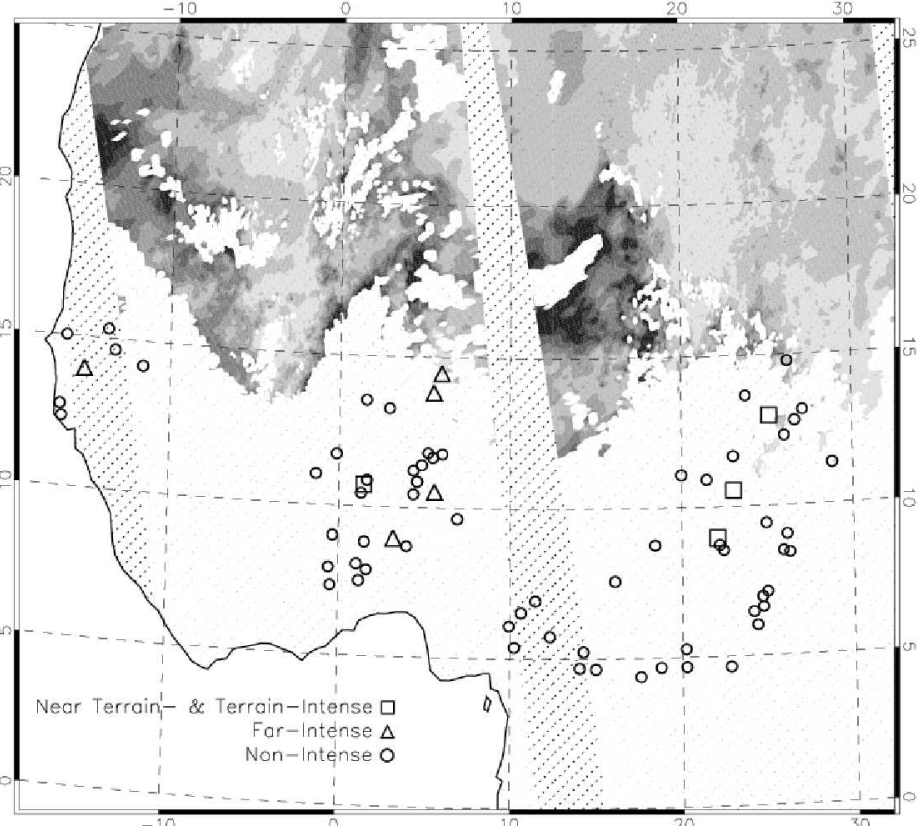

Optical Depth $\left(\mathrm{kgm}^{3} \mathrm{~kg}^{-1} \mathrm{~m}^{-3}\right)$

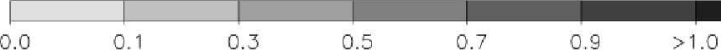

Figure 7. Contour plots of aerosol optical depth in optical depth units $\left(\mathrm{kg} \mathrm{m}^{3} \mathrm{~kg}^{-1} \mathrm{~m}^{-3}\right)$ for a) 23 May, b) 23 Jun, c) 24 Jul, d) 23 Aug. Gray shades indicate detectable dust over land. Areas in white are either over ocean or below instrument sensitivity over land. Dotted areas denote data dropouts and gaps between Aqua overflights. Intense and non-intense cases for each day are overplotted with the same symbol legend as Figure 5. 

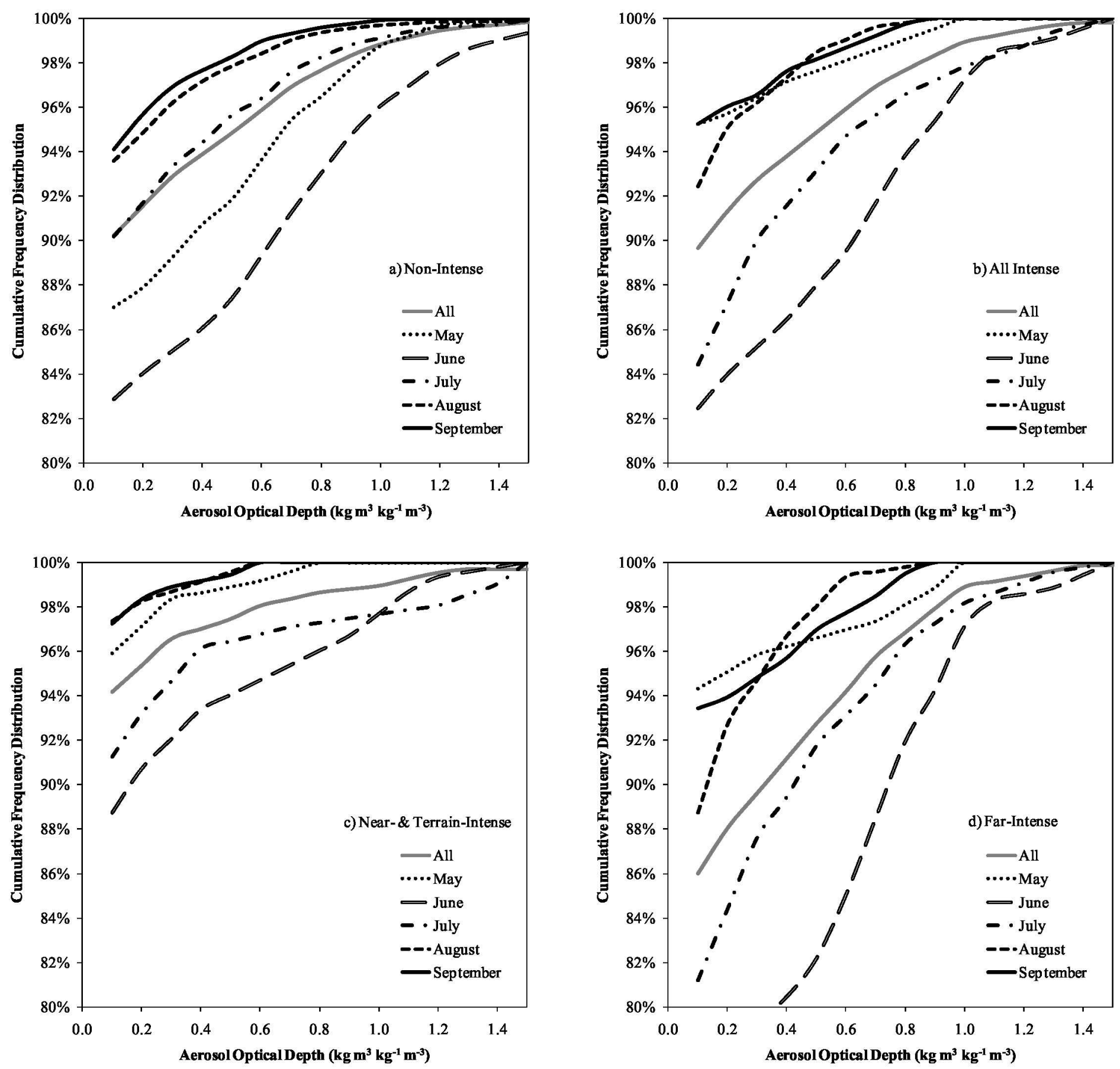

Figure 8. Cumulative frequency distributions of aerosol optical depth for each month and the seasonal mean for a) non-intense cases, b) all intense cases, c) near- and terrain-intense cases, d) far-intense cases. In all panels, the seasonal mean is a solid gray line, and the months are plotted in black: May (dotted), June (long, open dashes), July (dash-dot), August (short dashes), September (solid line). Because some bins contain few cases, the curves are not smooth. 
a) $200 \mathrm{hPa} \mathrm{U}-$ Wind $\left(\mathrm{ms}^{-1}\right)$ Hovmöller $[6.75 \mathrm{~N}-14.625 \mathrm{~N}]$

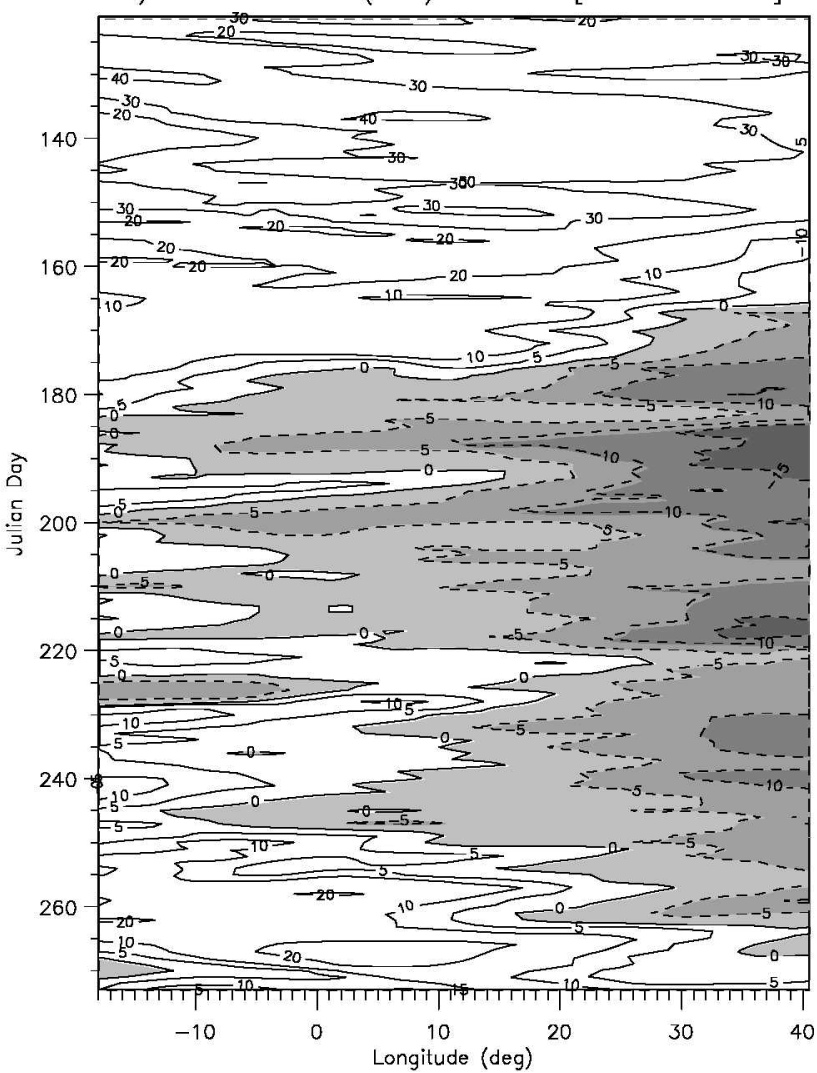

b) $200 \mathrm{hPa} \mathrm{V}$-Wind $\left(\mathrm{ms}^{-1}\right)$ Hovmöller $[6.75 \mathrm{~N}-14.625 \mathrm{~N}]$

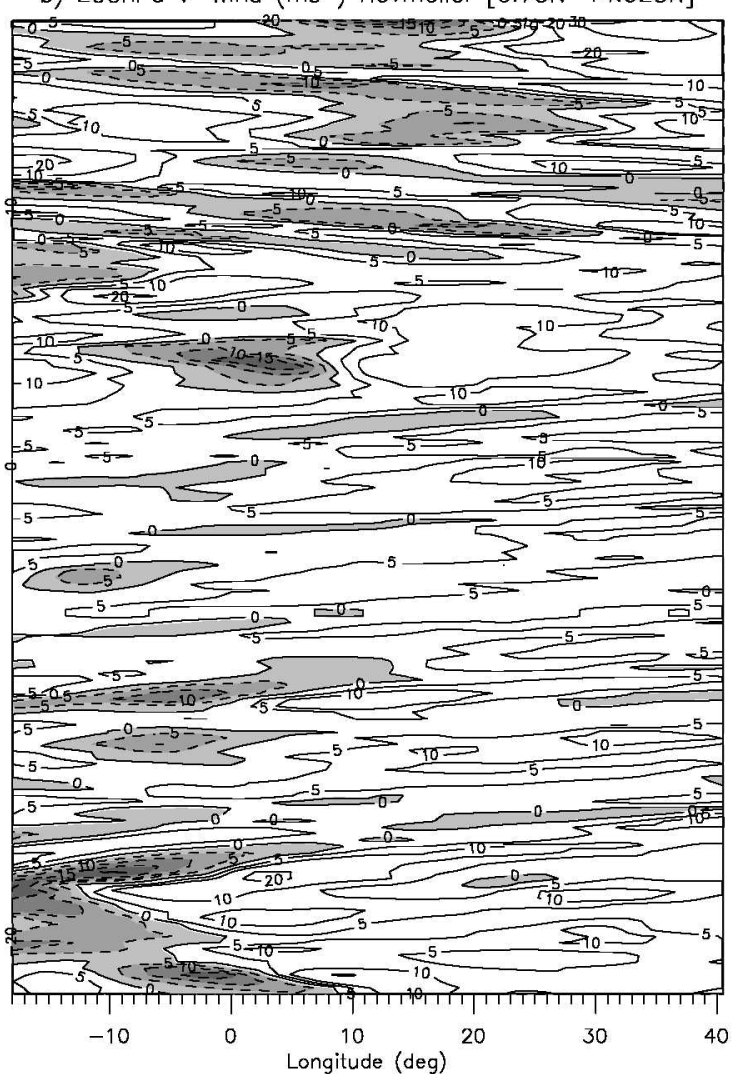

c) 2003 Daily Count of Convective Systems

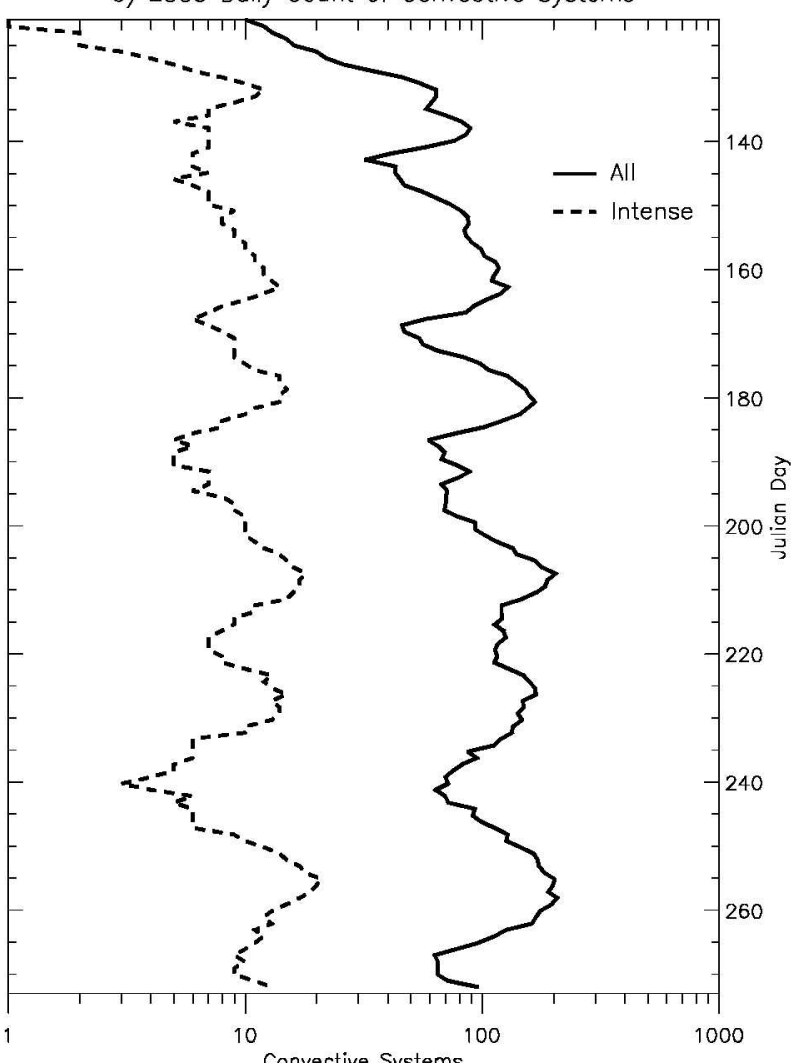

Figure 9. Hovmöller plots for the latitude band $6.75^{\circ} \mathrm{N}-14.625^{\circ} \mathrm{N}$ for a) 200 -hPa zonal (U) winds with easterly winds shaded, b) 200 $\mathrm{hPa}$ meridional (V) winds with northerly winds shaded. In c) time series of the 5-day running mean of daily total convective systems (all case types, solid line) and daily total intense convective systems (dashed line). All panels use the same time scale. 


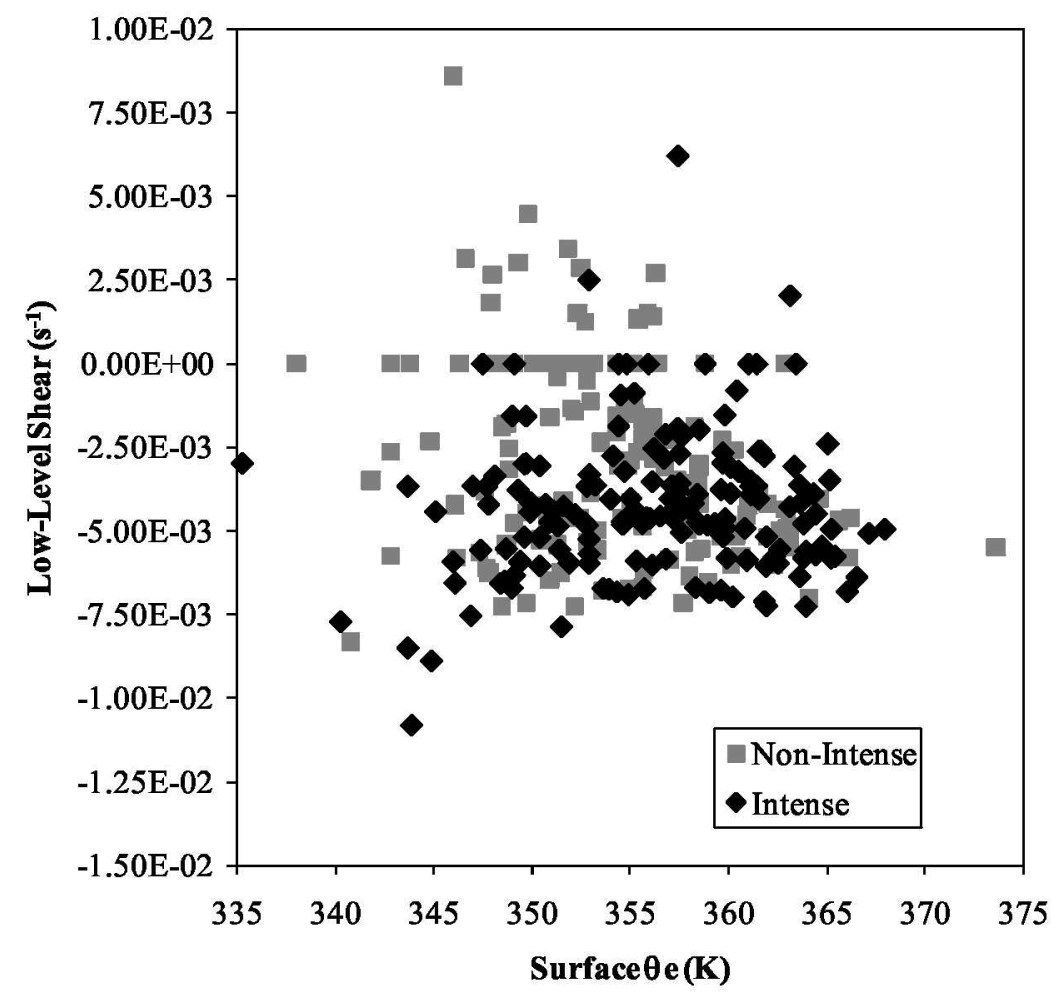

Figure 10. Scatter plot of surface $\theta_{\mathrm{e}}(\mathrm{K})$ vs. low-level shear $\left(\mathrm{s}^{-1}\right)$ for the in-situ intense (black diamond) and non-intense (gray square) cases. 


\begin{tabular}{|c|c|c|}
\hline Case Type & Criteria & Number of Cases \\
\hline 1. Near-terrain intense & $\begin{array}{l}\text { Minimum PCT } \leq 135 \mathrm{~K} \\
\text { Within } 6 \mathrm{~h} \times 700-\mathrm{hPa} \\
\text { wind of nearest } 500-\mathrm{m} \\
\text { contour }\end{array}$ & 618 \\
\hline 2. Terrain-intense & $\begin{array}{l}\text { Minimum } \mathrm{PCT} \leq 135 \mathrm{~K} \\
\text { On or within a } 500-\mathrm{m} \\
\text { contour }\end{array}$ & 577 \\
\hline 3. Far-intense & $\begin{array}{l}\text { Minimum } \mathrm{PCT} \leq 135 \mathrm{~K} \\
\text { Does not meet terrain } \\
\text { criterion of } 1 \text { or } 2 .\end{array}$ & 880 \\
\hline 4. Non-intense, local analysis & $\begin{array}{l}\text { Minimum PCT }>135 \mathrm{~K} \\
\text { Within } 0.25^{\circ} \text { of nearest } \\
500-\mathrm{m} \text { contour }\end{array}$ & 2995 \\
\hline Non-intense, regional analysis & Minimum PCT $>135 \mathrm{~K}$ & 13696 \\
\hline
\end{tabular}

Table 1. The four case types used in the analysis. Cases were classified by minimum PCT and proximity to high terrain $(\geq 500 \mathrm{~m})$. 


\begin{tabular}{lcccc}
\hline Location & Station ID & Soundings & \% Completed & $\begin{array}{c}\text { Observation } \\
\text { Times (Z) }\end{array}$ \\
\hline Agadez & 61024 & 128 & $84 \%$ & 9 \\
Bamako & 61291 & 260 & $85 \%$ & 0,12 \\
Bangui & 64650 & 90 & $29 \%$ & 0,12 \\
Dakar & 61641 & 248 & $81 \%$ & 9,21 \\
Douala & 64910 & 189 & $62 \%$ & 0,12 \\
N'Djamena & 64700 & 6 & $2 \%$ & 0,12 \\
Niamey & 61052 & 268 & $88 \%$ & 0,12 \\
Ouagadougou & 65503 & 31 & $20 \%$ & 12 \\
\hline
\end{tabular}

Table 2. Status information of the 8 sounding sites. "\% Completed" represents how many soundings were completed vs. the number that could have been launched. It was calculated by dividing the number of soundings in column 3 by the product of the number of days in the study period (153) and the number of observation times (1 or 2). 


\begin{tabular}{lrrrrrrrrrr}
\hline $\begin{array}{l}\text { Case } \\
\text { Type }\end{array}$ & $\begin{array}{r}\text { Min. } \\
\text { PCT } \\
(\mathrm{K})\end{array}$ & $\begin{array}{r}\text { AEJ } \\
\text { speed } \\
\left(\mathrm{ms}^{-1}\right)\end{array}$ & $\begin{array}{r}\text { AEJ } \\
\text { hight } \\
(\mathrm{m})\end{array}$ & $\begin{array}{r}\text { LL } \\
\text { shear } \\
\times 10^{-3} \\
\left(\mathrm{~s}^{-1}\right)\end{array}$ & $\begin{array}{r}\text { ML } \\
\text { shear } \\
\times 10^{-4} \\
\left(\mathrm{~s}^{-1}\right)\end{array}$ & $\begin{array}{r}\text { DL } \\
\text { shear } \\
\times 10^{-4} \\
\left(\mathrm{~s}^{-1}\right)\end{array}$ & $\begin{array}{r}\text { Surface } \\
\theta_{\mathrm{e}}(\mathrm{K})\end{array}$ & $\begin{array}{r}850 \mathrm{hPa} \\
\theta_{\mathrm{e}}(\mathrm{K})\end{array}$ & $\begin{array}{r}\text { BL } \theta_{\mathrm{e}} \\
(\mathrm{K})\end{array}$ & $\begin{array}{r}\text { No. of } \\
\text { cases }\end{array}$ \\
\hline $\begin{array}{l}\text { Non- } \\
\text { Intense }\end{array}$ & 254 & 9.4 & 2970 & -2.8 & -2.8 & 9.7 & 354 & 338 & 344 & 152 \\
$\begin{array}{l}\text { Intense } \\
\mathrm{p}-\end{array}$ & 112 & 11.6 & 3180 & -4.4 & -3.3 & 9.6 & 356 & 338 & 344 & 168 \\
value & & $<0.01$ & 0.01 & $<0.01$ & 0.46 & 0.48 & $<0.01$ & 0.43 & 0.49 & \\
$\begin{array}{l}\text { Near- } \\
\text { terrain }\end{array}$ & 113 & 10.6 & 3090 & -3.9 & -5.7 & 10.7 & 358 & 341 & 347 & 52 \\
$\begin{array}{l}\text { Terrain } \\
\text { Far- }\end{array}$ & 101 & 11.8 & 3260 & -4.2 & -11.5 & 5.5 & 361 & 338 & 347 & 7 \\
Intense & 111 & 12.1 & 3220 & -4.6 & -1.6 & 9.3 & 355 & 339 & 345 & 109 \\
\hline
\end{tabular}

Table 3. Summary of thermodynamic variables for in-situ sounding cases. The shear layers for low-level (LL), mid-level (ML), and deep-layer (DL) are defined in Section 2. Values for shear and $\theta_{\mathrm{e}}$ are category means. Minimum PCT is the median value. The first two rows are nonintense cases vs. intense cases, all case types. The third row contains $p$-values for one-tailed intense vs. non-intense hypothesis tests. Significant results at $\alpha=0.05$ where $\mu_{\text {intense }}>\mu_{\text {non-intense }}$ are in bold. Significant results at $\alpha=0.05$ where $\mu_{\text {intense }}<\mu_{\text {non-intense }}$ are in bold italics. The last three rows compare the intense case types. 


\begin{tabular}{|c|c|c|c|c|c|c|c|}
\hline $\begin{array}{l}\text { Case } \\
\text { Type }\end{array}$ & $\begin{array}{l}\text { Min. } \\
\text { PCT } \\
\text { (K) }\end{array}$ & $\begin{array}{l}700 \mathrm{hPa} \\
\text { speed } \\
\left(\mathrm{ms}^{-1}\right)\end{array}$ & $\begin{array}{l}\text { LL } \\
\text { shear } \\
\times 10^{-3} \\
\left(\mathrm{~s}^{-1}\right)\end{array}$ & $\begin{array}{l}\text { Surface } \\
\theta_{\mathrm{e}}(\mathrm{K})\end{array}$ & $\begin{array}{l}850 \mathrm{hPa} \\
\theta_{\mathrm{e}}(\mathrm{K})\end{array}$ & $\begin{array}{l}\operatorname{BL} \theta_{e} \\
(\mathrm{~K})\end{array}$ & $\begin{array}{l}\text { No. of } \\
\text { cases }\end{array}$ \\
\hline $\begin{array}{l}\text { Non- } \\
\text { Intense }\end{array}$ & 253 & 6.7 & -2.6 & 344 & 328 & 335 & 2843 \\
\hline Intense & 113 & 8.4 & -3.2 & 346 & 330 & 337 & 1907 \\
\hline $\begin{array}{l}p- \\
\text { value }\end{array}$ & & $<0.01$ & $<0.01$ & $<0.01$ & $<0.01$ & $<0.01$ & \\
\hline $\begin{array}{l}\text { Near- } \\
\text { terrain }\end{array}$ & 113 & 8.1 & -3.1 & 344 & 330 & 336 & 566 \\
\hline Terrain & 113 & 8.2 & -3.1 & 344 & 330 & 336 & 570 \\
\hline $\begin{array}{l}\text { Far- } \\
\text { Intense }\end{array}$ & 112 & 8.8 & -3.2 & 348 & 329 & 337 & 771 \\
\hline $\begin{array}{l}\text { p- } \\
\text { value }\end{array}$ & & $<0.01$ & 0.08 & $<0.01$ & $<0.01$ & $<0.01$ & \\
\hline
\end{tabular}

Table 4. Summary of thermodynamic variables for EOA-sounding cases. The table layout is similar to Table 3, except that only the low-level (surface to $700-\mathrm{hPa}$ ) shear is reported, and the last row contains p-values for far-intense vs. terrain and near-terrain intense case types. 


\section{An Analysis of the Environments of Intense Convective Systems in West Africa in 2003}

Stephen D. Nicholls (Rutgers University)

Karen I. Mohr (GSFC, Code 613.1)

December, 2009, Submitted to Monthly Weather Review

Intense, multi-cellular organized convection delivers an important share of the seasonal precipitation in West Africa. We used a combination of surface and space-based observations from TRMM and Aqua and operational analysis products from the ECMWF to identify and classify convective systems that occurred in West Africa during the 2003 wet season (May-September) and characterize their local and regional environments. Our analysis compared the environments of cases with and without intense convection.

To characterize the local environment, we tested a series of variables and intensity prediction indices used by U.S. forecasters in severe weather forecasting. Only a few of these metrics produced statistically significant results. The speed of the regional mid-level jet, the magnitude of the low-level shear, and the atmospheric instability were greater for the intense cases compared to the non-intense cases. For these few significant metrics, the differences between the means were small, but the variances were large. For example, the mean jet speed for the intense cases was $11.6 \mathrm{~m} \mathrm{~s}^{-1}$ versus $9.4 \mathrm{~m} \mathrm{~s}^{-1}$ for the non-intense cases, although the proportion of intense cases with jet speeds above $10 \mathrm{~m} \mathrm{~s}^{-1}$ was $65 \%$ versus $43 \%$ for the non-intense cases.

To characterize the regional environment, we examined the relationship of our cases to synopticscale waves, to Saharan dust outbreaks, and to regional circulation features such as the movement of the West African monsoon. The majority of our intense cases occurred in $5^{\circ}$ zone just south of the intersection of the moist monsoon southerly winds and the dry northerly Saharan winds. This zone maximizes warm surface temperatures, humidity, and low-level wind shear from the mid-level jet. Because a large number of non-intense cases also occur in this zone, mapping the zone only suggests areas where intense convection is more likely to develop.

Determining the likelihood that intense convective systems will develop during the West African wet season does not fall into place as a straightforward forecasting recipe. Case intensity was not consistently proportional to atmospheric instability, to low-level wind shear, or to the combination, making them unreliable for directly predicting intensity in an uncontrolled operational framework. 